\title{
Reversible Behavioral Phenotypes in a Conditional Mouse Model of TDP-43 Proteinopathies
}

\author{
Julio A. Alfieri, Natalia S. Pino, and $\oplus^{\circ}$ Lionel M. Igaz \\ Neuronal Physiopathology Laboratory, Systems Neuroscience Group, IFIBIO Houssay, University of Buenos Aires School of Medicine, Buenos Aires \\ (C1121ABG), Argentina
}

\begin{abstract}
Transactive response DNA-binding protein 43 (TDP-43) mislocalization and aggregation are hallmark features of amyotrophic lateral sclerosis and frontotemporal dementia (FTD). We have previously shown in mice that inducible overexpression of a cytoplasmically localized form of TDP-43 (TDP-43- $\Delta$ NLS) in forebrain neurons evokes neuropathological changes that recapitulate several features of TDP-43 proteinopathies. Detailed behavioral phenotyping could provide further validation for its usage as a model for FTD. In the present study, we performed a battery of behavioral tests to evaluate motor, cognitive, and social phenotypes in this model. We found that transgene $(\mathrm{Tg})$ induction by doxycycline removal at weaning led to motor abnormalities including hyperlocomotion in the open field test, impaired coordination and balance in the rotarod test, and increased spasticity as shown by a clasping phenotype. Cognitive assessment demonstrated impaired recognition and spatial memory, measured by novel object recognition and Y-maze tests. Remarkably, TDP-43$\Delta$ NLS mice displayed deficits in social behavior, mimicking a key aspect of FTD. To determine whether these symptoms were reversible, we suppressed Tg expression for $14 \mathrm{~d}$ in 1.5-month-old mice showing an established behavioral phenotype but modest neurodegeneration and found that motor and cognitive deficits were ameliorated; however, social performance remained altered. When Tg expression was suppressed in 6.5-month-old mice showing overt neurodegeneration, motor deficits were irreversible. These results indicate that TDP-43- $\Delta$ NLS mice display several core behavioral features of FTD with motor neuron disease, possibly due to functional changes in surviving neurons, and might serve as a valuable tool to unveil the underlying mechanisms of this and other TDP-43 proteinopathies.
\end{abstract}

Key words: Behavioral phenotypes; frontotemporal dementia; neurodegeneration; proteinopathies; TDP-43; transgenic mice

\section{Introduction}

Neurodegenerative diseases characterized by neuronal and glial inclusions mainly composed of insoluble transactive response DNA-binding protein 43 (TDP-43) are now collectively referred to as TDP-43 proteinopathies. Frontotemporal lobar degeneration with ubiquitinated TDP-43 inclusions (FTLD-TDP) and amyotrophic lateral sclerosis (ALS) are the most prevalent TDP-43 proteinopathies (Neumann et al., 2006). In the past few years, the identification of mutations in TARDBP (the gene encoding TDP-43) that are linked to both sporadic and familial ALS

Received May 7, 2014; revised Sept. 29, 2014; accepted 0ct. 3, 2014.

Author contributions: J.A.A. and L.M.I. designed research; J.A.A., N.S.P., and L.M.I. performed research; J.A.A. and L.M.I. analyzed data; J.A.A. and L.M.I. wrote the paper.

The authors declare no competing financial interests.

This work was supported by research grants to L.M.I. from Agencia Nacional de Promoción Científica y Tecnológica (ANPCyT) (PICT-PRH 2009-0073 and PICT 2011-1727), the International Brain Research Organization (IBRO Return Home Fellowship), Fundación Florencio Fiorini, Fundación Alberto Roemmers, and the University of Buenos Aires (UBACyT). L.M.I. is a member of Consejo Nacional de Investigaciones Científicas y Técnicas (CONICET). J.A. was supported by a doctoral fellowship from CONICET. We thank Virginia M.-Y. Lee and John Q. Trojanowski (University of Pennsylvania) for the kind gift of TDP-43- $\Delta$ NLS mice (these mice were developed through support by National Institutes of Health Grants AG032953 and AG-17586 and the Koller Foundation for ALS Research); P. Bekinschtein, V. Della-Maggiore, T. Falzone, F. Ledda, J. Medina, G. Murer, G. Paratcha, N. Piriz, and N. Weisstaub for helpful discussion of the manuscript; and Verónica Ríos and María Eugenia Ribet for husbandry support.

Correspondence should be addressed to Dr. Lionel Muller Igaz, Grupo de Neurociencia de Sistemas, IFIBIO Houssay, Facultad de Medicina, UBA, Paraguay 2155 7mo piso, Buenos Aires (C1121ABG), Argentina. E-mail: Imuller@fmed.uba.ar.

DOI:10.1523/JNEUROSCI.1918-14.2014

Copyright $\odot 2014$ the authors $\quad 0270-6474 / 14 / 3415244-16 \$ 15.00 / 0$ indicated that alteration of TDP-43 can cause neurodegeneration directly (Gitcho et al., 2008; Kabashi et al., 2008; Rutherford et al., 2008; Sreedharan et al., 2008; Yokoseki et al., 2008).

A variety of TDP-43 mouse models have been recently developed and the most consistent behavioral features in these animals are motor phenotypes (for review, see Tsao et al., 2012). In some specific models, cognitive impairment was also detected (Tsai et al., 2010; Swarup et al., 2011; Caccamo et al., 2012). Most of these animal models are driven by pan-neuronal promoters with constitutive expression, which makes it difficult to assess other aspects within the behavioral domain affected by motor deficits and also to circumvent the possible prenatal or early postnatal effects of TDP-43 dysregulation (Cannon et al., 2012). To avoid these issues and to study the contribution of TDP-43 mislocalization in disease progression, we recently developed an inducible transgenic (Tg) mouse that overexpresses the cytoplasmic form TDP$43-\Delta$ NLS (Igaz et al., 2011). The use of the CaMKII $\alpha$ promoter provides selectivity of expression at the cellular level. In this case, TDP-43- $\Delta$ NLS was enriched in forebrain neurons, allowing us to study both behavioral and neuropathological phenotypes without early mortality or confounds caused by the inability to perform cognitive or social tasks due to paralysis.

We previously reported that these animals develop timedependent, region-specific neuronal loss, corticospinal tract neurodegeneration and a spastic motoric phenotype. In addition, we described profound changes in cortical gene expression (Igaz et 
A
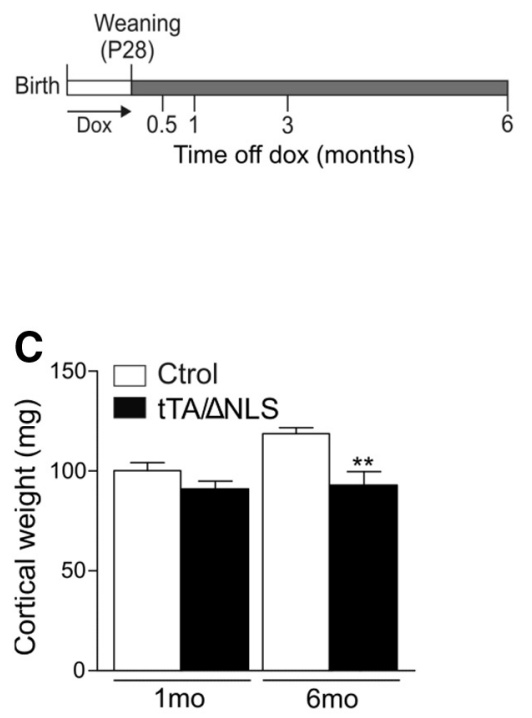

E

\begin{tabular}{ccc}
\hline Test & Ctrol & tTA/ $\Delta$ NLS \\
\hline Visual cliff response (\%) & $83.3(10 / 12)$ & $87.5(7 / 8) \mathrm{ns}$. \\
Visual placing response & $1.8 \pm 0.1$ & $1.2 \pm 0.2 \mathrm{~ns}$. \\
\hline
\end{tabular}

Figure 1. Progressive cortical and hippocampal atrophy in TDP-43- $\Delta N L S$ transgenic mice. $A$, Experimental design: transgene expression was activated at weaning (P28) by removing Dox from water, followed by analysis at the indicated time points. B, Body weight curve for non-TDP-43- expressing control (Ctrol) mice ( $\mathrm{nTg}, \mathrm{tTA}, \Delta \mathrm{NLS}$ ) and bigenic mice (tTA/ $\Delta \mathrm{NLS}$ ) assessed at different times off Dox ( $n=10$ per group). ${ }^{*} p<0.05$; ${ }^{* * *} p<0.001$, two-way ANOVA/Bonferroni post hoc analysis. $C$, $D$, Cerebral cortex and hippocampus weights for Ctrol and tTA/ $\Delta$ NLS mice at 1 and 6 months off Dox ( $n=5$ per group). ${ }^{*} p<0.05 ;{ }^{* *} p<0.01$ significantly different from Ctrol group (Student's $t$ test). The data are displayed as mean \pm SEM. $E$, Visual perception. Percentage of animals stopping at the edge in the visual cliff test and reaction score (mean $\pm S E M)$ in the visual placing response. Bigenic mice did not show statistically significant impairments in visual performance ( $\mathrm{ns}$, nonsignificant Mann-Whitney $U$ test; control, $n=12$; $\mathrm{tTA} / \Delta \mathrm{NLS}, n=8)$.

al., 2011). However, the specific contribution of TDP-43- $\Delta$ NLS expression at the behavioral level was not investigated. Here, we sought to perform both a detailed behavioral characterization and an assessment of neurodegeneration in these mice. Moreover, it is currently not known whether suppression of TDP-43 overexpression can arrest or reverse associated behavioral changes. To explore the consequences of reversible TDP-43$\Delta$ NLS expression, we induced the Tg at weaning and suppressed its expression at early ( 0.5 month) or late $(5.5$ months) time points to evaluate the relationship among behavioral abnormalities, regional neurodegeneration, and functional changes in TDP-43- $\Delta$ NLS-overexpressing neurons. Our data show that TDP-43- $\Delta$ NLS expression impairs multiple behavioral domains affected in FTD-motor neuron disease (MND), including motor, cognitive, and social functions. In addition, short-term suppression of TDP-43- $\Delta$ NLS expression reversed motoric and cognitive (but not social) phenotypes in young mice with limited neurodegeneration. These deficits could not be rescued by suppression in older mice displaying more degenerated brains.

These results suggest that TDP-43-mediated behavioral dysfunction is sustained by functional changes in populations of affected neurons independently of extensive neurodegeneration and that diverse symptoms might have different susceptibility to amelioration.

\section{Materials and Methods}

Transgenic mice

As described previously (Igaz et al., 2011), human TDP-43 (hTDP-43) Tg lines were generated by injection of linearized moPrP-tetP vector con- taining hTDP-43- $\triangle$ NLS cDNA into pronucleus of fertilized eggs from $\mathrm{C} 57 \mathrm{BL} / 6 \mathrm{~J} \times \mathrm{C} 3 \mathrm{HeJ}$ F1 matings. Monogenic tetO-TDP- $\Delta$ NLS4 mice were bred to Camk2a-tTA mice (Mayford et al., 1996; The Jackson Laboratory) generating nTg, tTA monogenic, single tetO-TDP-43 $\mathrm{Tg}$ mice (non-TDP-43 expressing control mice), and bigenic mice expressing hTDP-43$\Delta$ NLS (hereinafter referred to as tTA/DNLS). To avoid prenatal and postnatal developmental effects of Tg expression, breeding mice and pups were treated with $0.2 \mathrm{mg} / \mathrm{ml}$ doxycycline hyclate (Dox; sc-204734A; Santa Cruz Biotechnology) in drinking water unless otherwise stated. Tg expression was activated at weaning [postnatal day 28 (P28)] by removing Dox from water and mice were analyzed at different time points (Fig. 1A). For suppression experiments, mice were treated again with $0.2 \mathrm{mg} / \mathrm{ml}$ Dox in drinking water for the indicated times.

Genotyping from tail DNA was performed using the following primers: TDP-forward (TTGGTAATAGCAGAGGGGGTGGAG), MoPrP-reverse (TCCCCCAGCCTAGACCAC GAGAAT), Camk2a-tTA-forward (CGCTGT GGGGCATTTTACTTTAG), and Camk2atTA-reverse (CATGTCCAGATCGAAATCGTC). Tg lines were established by crossbreeding with C57BL/6J mice for 6-7 generations to homogenize genetic background. Each of the different age groups studied for all subsequent experiments contained Tg and control animals of either sex. The experimental protocol for this study was approved by the National Animal Care and Use Committee of the University of Buenos Aires.

\section{Tg suppression protocol}

Mice raised on Dox until P28 were treated again with Dox starting at 0.5 months $[1$ mo(sup) mice] or 5.5 months [6 mo(sup) mice] after weaning to suppress transgene expression for 2 weeks, and analyzed at 1 month or 6 months after weaning, respectively. These mice were compared with mice in which transgene expression was maintained until 1 month (1 mo mice) or 6 months (6 mo mice) after weaning.

\section{Behavioral studies}

Mice (male and female) were kept on a $12 \mathrm{~h}$ light/dark cycle and had ad libitum access to food and water. All behavioral tasks, except for the Y-maze spontaneous alternation, were performed during the light phase. All animals were allowed to habituate in the experimental room (with attenuated light and sound) for at least $1 \mathrm{~h}$ before the tests. All mazes and objects used in behavioral analysis were cleaned with ethanol $10 \%$ between test sessions.

Because all nonbigenic offspring (nontransgenic and both single transgenic mice) exhibited similar behavioral responses, we grouped these genotypes under the Control group to compare against the Bigenic phenotype mice for all subsequent behavioral tests and other experimental analysis.

Open field. Open field tests were performed for assessment of general exploratory locomotion in a novel environment. Mice were placed in a clear Plexiglas $(40 \times 40 \times 40 \mathrm{~cm})$ arena with white floor divided into 2 zones: periphery and center (comprising $50 \%$ of the total area centered). All activity was recorded for $20 \mathrm{~min}$ with a computer-linked video camera mounted above the testing box. Mouse position was determined by automatic video tracking (ANY-maze; Stoelting). Room illumination was kept at 50 lux. Total distance and center distance traveled by the mice was analyzed. Time bin analysis (every $5 \mathrm{~min}$ ) was used.

Rotarod. A rotarod apparatus (model 7600; Ugo Basile) was used to measure motor coordination and balance. For the fixed speed rotarod 
test (17 rpm), mice were given one or two practice trials and then placed on the rotating cylinder; a 3 min cutoff per session was used. For the accelerating rotarod test $(4-40 \mathrm{rpm}$ over $300 \mathrm{~s}), 4$ trials per test were performed during the test day, with a 2 min interval between trials. The latency to fall off the rotarod was recorded for both configurations. Mice that rotated passively were scored as fallen.

Clasping phenotype. hTDP-43- $\Delta$ NLS Tg mice and age-matched control mice were suspended by the tail $30 \mathrm{~cm}$ above an open cage for $30 \mathrm{~s}$, after which they were slowly lowered toward the bottom of the cage. A positive response was recorded for mice that clasped their limbs within $5 \mathrm{~s}$ of suspension while maintaining the clasping posture until lowered to the cage.

Novel object recognition. Each mouse was habituated to an empty Plexiglas arena $(40 \times 23 \times 15 \mathrm{~cm})$ for 2 consecutive days $(110$-min session the first day and 25 -min sessions the second day). On the third day (training), the mice were exposed to two identical objects placed at opposite ends of the arena for $10 \mathrm{~min}$. Twenty-four hours later (test day), the mice were allowed to explore 1 copy of the previously presented object (familiar) and a new object (novel) for $5 \mathrm{~min}$. All of the sessions were recorded using a camera mounted above the arena. Exploration was defined as pointing the head toward an object at a distance of $<2 \mathrm{~cm}$ from the object, with its neck extended and vibrissae moving. As far as we could determine, the objects had no natural relevance for the mice and they have never been associated with a reward. Turning around and sitting on the objects were not considered exploratory behaviors. The exploration time represents the percentage of time that mice spend exploring the object (familiar or novel) respect to the total exploration time (familiar + novel).

Step-through inhibitory (passive) avoidance. Inhibitory avoidance behavior was studied in a one-trial learning task that uses the natural preference of mice for a dark environment. The apparatus consists of a dark Plexiglas compartment $(20 \times 20 \times 15 \mathrm{~cm})$ with a stainless-steel grid floor and a small $(5 \times 5 \mathrm{~cm})$ illuminated, elevated platform attached to its front center. During training, each mouse was placed on the platform and received a footshock as it stepped into the dark compartment $(0.8$ $\mathrm{mA}, 50 \mathrm{~Hz}, 1 \mathrm{~s}$ ), as described previously (Boccia et al., 2004). The retention test was performed 1.5 or $48 \mathrm{~h}$ later. Each mouse was placed on the platform again and the step-through latency was recorded with a $300 \mathrm{~s}$ cutoff per session. In the retention test session, the footshock was omitted.

$Y$-maze spontaneous alternation test. The $\mathrm{Y}$-shaped maze consisted of three identical arms of transparent Plexiglas $(43 \times 4 \times 12.5 \mathrm{~cm})$ placed at $120^{\circ}$ angles to each other (Belforte et al., 2010). Mice were placed at the end of one arm facing the center and allowed to explore the maze freely for 8 min without training, reward, or punishment. All sessions were video recorded through a camera mounted above the maze and mouse position was tracked using ANY-maze software. Room illumination was kept at 30 lux. Entries into each arm were scored by an investigator and alternation behavior was defined as a complete cycle of consecutive entrances into each of the 3 arms without repetition. The percentage of spontaneous alternation was calculated as the number of alternations divided by the possible alternations [ \# alternations)/(total arm entries 2) $\times 100]$. Total entries were scored as an index of ambulatory activity in the $\mathrm{Y}$ maze and mice with scores $<12$ were excluded. All experiments were conducted during the initial dark phase (6:00 P.M. to 9:00 P.M.) to maximize exploratory behavior (Belforte et al., 2010).

Social interaction test. The social interaction test was performed as described previously (Brodkin et al., 2004; Depino et al., 2011). Briefly, the test apparatus consisted of a black Plexiglas rectangular box $(40.6 \times$ $15 \times 23 \mathrm{~cm}$ ) with three interconnected chambers that was placed under dim light (25 lux). The apparatus was covered with clean bedding. Before the start of each test, one of the end chambers was randomly designated the "nonsocial side" and the other the "social side." During the habituation phase, 2 identical clear Plexiglas cylinders (each $7 \mathrm{~cm}$ in diameter, $14 \mathrm{~cm}$ tall) with a black plastic cover on the top were placed in the apparatus, 1 in each end chamber. Animals (test mice) were placed in the central chamber and allowed to explore the apparatus for $5 \mathrm{~min}$. The cylinders had multiple small holes $(0.5 \mathrm{~cm}$ diameter $)$ to allow for auditory, visual, and olfactory investigation between test and stimulus mice.
After habituation, a stimulus mouse (a 21- to 28-d-old C57BL/6J male mouse) was placed into the cylinder on the side that had been designated the social side and a black plastic object was placed into de cylinder on the nonsocial side (nonsocial stimulus). The test mouse was able to freely explore the apparatus for $10 \mathrm{~min}$ (test phase). Time spent sniffing the social and nonsocial stimuli and time spent in each chamber was measured. All sessions were video recorded through a camera mounted above the testing box. Clean bedding was placed on the box before the next test.

Olfactory habituation/dishabituation. The ability to recognize an attractive, novel odor was assessed by the olfactory habituation/dishabituation task. As described previously (Belforte et al., 2010), each mouse was transferred individually into a clean cage containing fresh bedding 30 min before the test for habituation. Swabs were dipped and presented in the following order: tap water, almond extract (1:300), banana extract (1:300), and the bottom surface of a plastic cage containing a group of 5 male mice or 5 female mice (C57BL/6J) that had lived in the cage for $6 \mathrm{~d}$. During the test, each odor was presented 3 times consecutively for $2 \mathrm{~min}$. All sessions were video recorded and cumulative time spent sniffing the odorant in each presentation was quantified. Testing was conducted in a 30 lux illuminated room.

Self-grooming test. Self-grooming was evaluated in a clear Plexiglas box $(26 \times 16 \times 14.5 \mathrm{~cm})$. All activity was recorded by a video camera mounted above the testing box for $15 \mathrm{~min}$. Cumulative time spent in grooming was measured.

Hanging wire grip test. Grip strength was assessed using a standard wire cage with masking tape placed around the perimeter of the lid to prevent the mouse from walking off the edge. The hanging wire test was performed by placing the mouse on the top of the wire cage lid, the lid was shaken lightly three times to cause the mouse to grip the wires, and then the lid was turned upside down. The upside-down lid was hold at a height $\sim 20 \mathrm{~cm}$ above a cage containing fresh bedding. The latency to fall off the wire lid was quantified. A $60 \mathrm{~s}$ cutoff time was used.

Visual perception. Visual perception was evaluated in the visual cliff test (Salinger et al., 2003; Belforte et al., 2010) and with the visual placing response (Metz and Schwab, 2004). In the visual cliff test, a box with a simulated ledge was used. The surface of the box $(30 \times 30 \mathrm{~cm})$ and ledge ( $60 \mathrm{~cm}$ high) were covered with a black-and-white checkerboard pattern $(2.5 \times 2.5 \mathrm{~cm})$ to emphasize the ledge dropoff. A piece of clear Plexiglas spanned the ledge, resulting in the visual appearance of a cliff. The trial began with the placement of a single mouse in the rear left corner of the visually shallow side of the box facing away from the apparent ledge. The behavior was scored as "positive" when the mouse stopped at the virtual edge before attempting to cross. Visually impaired animals walk across the Plexiglas without stopping. The percentage of animals stopping at the edge was quantified. Each animal was tested only once. For the visual placing response, mice were held by the tail and lowered toward a solid surface without any contact to the vibrissae. As the head approached the table surface, the mouse extended the paws toward the surface to reach for a soft landing. Visually impaired mice do not see the surface coming and do not extend the paws. The mean response was rated in 1 trial with a scoring system as follows: $0=$ no observable placing response, $1=\mathrm{a}$ weak placing response, and $2=$ a clear placing response. For both tests, vibrissae were removed to eliminate tactile placing responses.

\section{Brain tissue collection}

After deep anesthesia with $5 \%$ chloral hydrate $(1 \mathrm{ml} / 30 \mathrm{~g})$, the mice were perfused transcardially with ice-cold PBS $(0.1 \mathrm{M}), \mathrm{pH} 7.4$, supplemented with $10 \mathrm{U} / \mathrm{ml}$ heparin. The brains were immediately extracted and cut sagitally into two hemispheres. One hemisphere was fixed overnight in $4 \%$ PFA and then cryoprotected in $10 \%$ and $30 \%$ sucrose in PBS for immunofluorescence analyses. The other hemisphere was further dissected into cerebral cortex, hippocampus, cerebellum, olfactory bulb, and the rest of the tissue (subcortical structures, brainstem) and then immediately frozen on dry ice and kept at $-80^{\circ} \mathrm{C}$ for biochemical analysis and weight measurements.

\section{Antibodies}

Antibodies used in this study were as follows: rabbit anti-TDP-43 polyclonal antibody raised to amino acids 394-414 (C-t TDP-43 pAb) was 

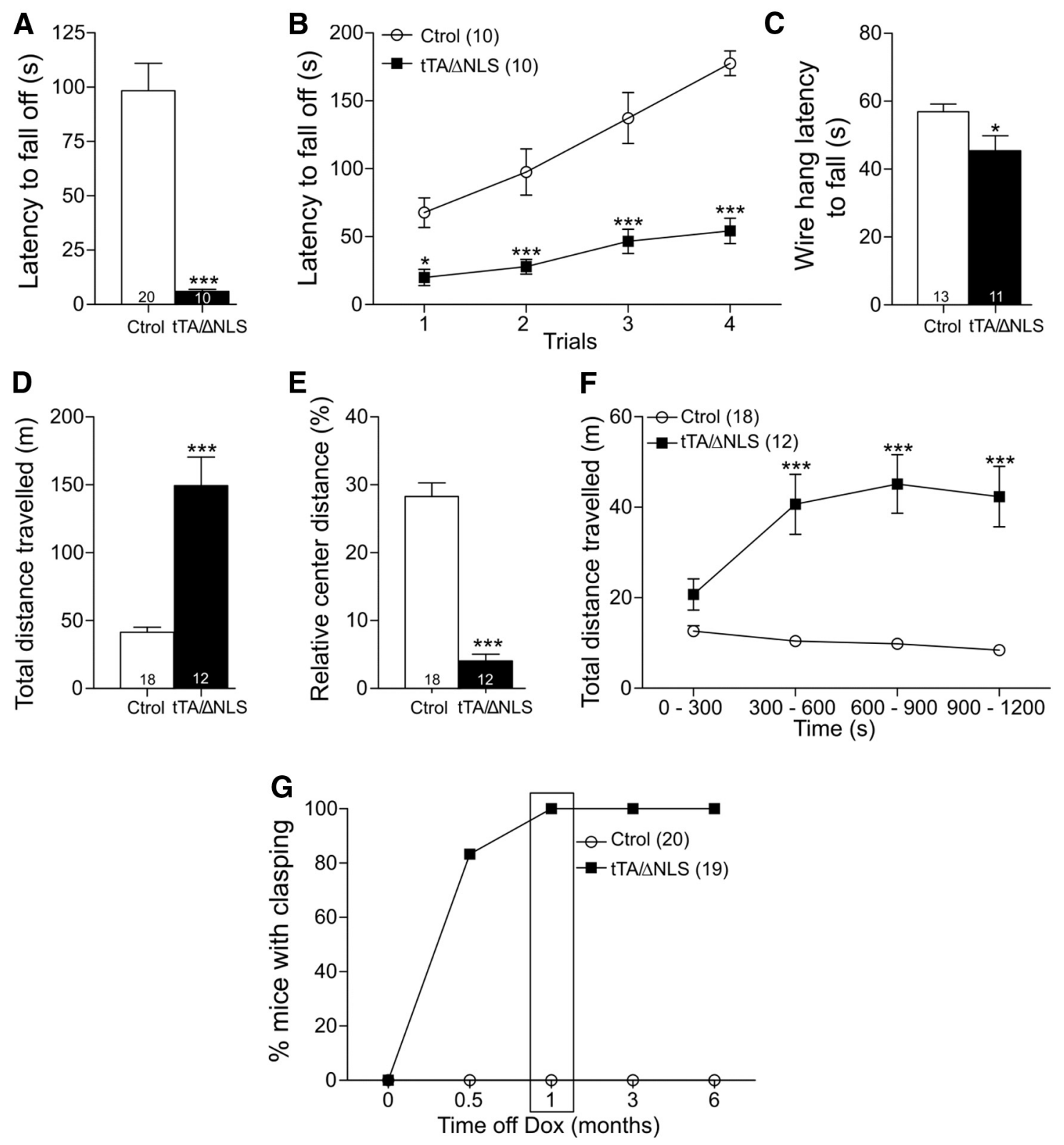

Figure 2. TDP-43- $\Delta$ NLS transgenic mice develop motor abnormalities. $A, B$, Rotarod performance. Bigenic mice demonstrated an impaired ability to remain on the rod compared with Ctrol mice. $A$, Fixed speed rotarod test (17 rpm). Mice were given 1 or 2 practice trials and then placed on the rotating cylinder; a 3 min cutoff per session was used $\left({ }^{* * *} p<0.001\right.$ significantly different from Ctrol group, Student's t test). $\boldsymbol{B}$, Accelerated rotarod test $(4-40 \mathrm{rpm} / 5 \mathrm{~min})$. Four trials per test were performed during the test day with a 2 min interval between trials. Latency to fall off the rotarod was recorded $\left({ }^{*} p<0.05 ;{ }^{* * *} p<0.001\right.$, repeated measures two-way ANOVA/Bonferroni post hoc test). $C$, Hanging wire grip test. Grip strength was assessed using a standard wire cage turned upside down. The latency to fall off the wire lid was quantified. A 60 s cutoff time was used. ${ }^{*} p<0.05$ significantly different from Ctrol group (Student's $t$ test). $\boldsymbol{D}-\boldsymbol{F}$, Exploratory and locomotor activity in a novel environment was assessed by a 20 min session in an open field chamber. TDP-43- $\Delta$ NLS Tg animals displayed severe hyperlocomotion. Bar graphs show the total distance traveled $(\boldsymbol{D})$ and relative center distance $(\boldsymbol{E}){ }^{* * *} p<0.001$ significantly different from (trol group, Student's $t$ test). $\boldsymbol{F}$, Total distance traveled in time segments of $300 \mathrm{~s}\left({ }^{* * *} p<0.001\right.$, repeated-measures ANOVA/Bonferroni post hoc test). $\boldsymbol{G}$, Percentage of mice with clasping phenotype at different times off Dox. Motor behavior in $\boldsymbol{A}-\boldsymbol{F}$ was analyzed at 1 month off Dox. Number of animals is indicated in parentheses or inside plot bars. Data represent mean \pm SEM.

described previously (Igaz et al., 2008), a human specific mouse antiTDP-43 monoclonal antibody raised to amino acids 1-260 (60019-2; Proteintech), a mouse anti-NeuN monoclonal antibody (MAB377; Millipore Bioscience Research Reagents), and an anti-GAPDH mouse monoclonal antibody (6C5; Advanced ImmunoChemical).

\section{Immunofluorescence}

Fixed frozen hemispheres were cut $(30-50 \mu \mathrm{m})$ using a sliding freezing microtome (SM 2010R; Leica) and stored at $-20^{\circ} \mathrm{C}$ in cryoprotecting solution (50\% glycerol, 50\% PBS) until use. After PBS (0,01 M) washes, coronal free-floating sections were permeabilized with $1 \%$ Triton X-100 in PBS for $1 \mathrm{~h}$, blocked for $1 \mathrm{~h}$ with $0.3 \%$ Triton $\mathrm{X}-100$ and $5 \%$ goat serum in PBS, and incubated overnight with primary antibodies (diluted in $0.3 \%$ Triton $\mathrm{X}-100$ and $3 \%$ goat serum in PBS) at $4^{\circ} \mathrm{C}$ with the indicated dilutions: rabbit anti-TDP-43 1:30000, anti-hTDP-43 1:10000, and antiNeuN 1:1000. After washes, primary antibodies were visualized with secondary antibodies conjugated with Alexa Fluor 488 (Invitrogen) and rhodamine (Jackson Laboratories) diluted in $0.3 \%$ Triton X-100 and 5\% goat serum in PBS for $4 \mathrm{~h}$ at room temperature and nuclear counterstaining was done with Hoechst $33342(2 \mu \mathrm{g} / \mathrm{ml})$. Sections were mounted onto gelatin-coated slides using $30 \%$ glycerol in PBS and images were captured with an Olympus DP71 camera attached to an Olympus IX-81 microscope or a confocal microscope (Olympus FV1000) with Fluoview 
2.1 software (Olympus). All of the micrographs show images representative of the total cell population.

\section{Thickness measurement and cell counting} Coronal brain sections were immunostained for the neuronal marker NeuN. Digital images were taken using the $4 \times$ or $40 \times$ objectives under identical illumination and exposure settings. The captured images were stored in 24bit TIF format and processed using ImageJ software (version 1.46r). For thickness analysis the cross-length of somatosensory and motor cortex ( $4 \times$ images), or hippocampal dentate gyrus granule cell layer ( $40 \times$ images) was measured ( $n=8-10$ mice per group). The quantifications of NeuN-positive cortical neurons were performed manually in a $462 \times 348 \mu \mathrm{m}$ area using $40 \times$ images of immunostained brain sections of somatosensory, motor and prefrontal cortex (layer $\mathrm{V}$, bregma -2.06, 1.18, $1.94 \mathrm{~mm}$, respectively; Paxinos and Franklin, 2008). Two images per region of interest per mouse were taken ( $n=8-10$ mice per group).

\section{SDS-PAGE and immunoblot analysis}

Tissues were extracted with 10 volumes $(\mathrm{ml} / \mathrm{g}$ tissue) of RIPA buffer ( $0.1 \%$ SDS, $1 \%$ NP- 40 , $0.5 \%$ sodium deoxycholate, 5 mм EDTA, 150 $\mathrm{mm} \mathrm{NaCl}, 50$ mм Tris-HCl, $\mathrm{pH}$ 8.0) containing protease and phosphatase inhibitor mixture (Roche), sonicated, and centrifuged at 13000 $\mathrm{rpm}$ for $20 \mathrm{~min}$ at $4^{\circ} \mathrm{C}$. Protein concentrations were determined using the BCA assay kit (Pierce). Equal amounts $(30 \mu \mathrm{g})$ of samples were subsequently resolved on $10 \%$ SDSPAGE gels and transferred onto PVDF membranes (Immobilon-P; Millipore). Primary antibodies were used as follows: 1:20 000 rabbit anti-TDP-43 and 1:2000 anti-GAPDH. Membranes were probed with corresponding secondary antibodies (coupled to HRP, 1:5000; Jackson ImmunoResearch) and visualized with enhanced chemiluminescence (ECL; Pierce). GAPDH was used as loading control. Digital images were acquired using an ImageQuant RT ECL Imager (GE Healthcare). Quantification of band intensity was performed using ImageJ software.

\section{Statistical analysis}

Data are expressed as means \pm SEM. Statistical analysis of behavioral tests was performed using student's $t$ tests when comparing only two groups on one behavioral measure and a oneway ANOVA followed by Newman-Keuls multiple-comparison post hoc test when comparing three or more groups. For visual cliff and visual placing tests, nonparametric MannWhitney $U$ test was used. For the olfactory habituation/dishabituation task, accelerated rotarod and open field time segment analysis repeated-measures ANOVA followed by Bonferroni's multiple-comparison post hoc test was used. For clasping analysis and the inhibitory avoidance task, nonparametric Kruskal-Wallis one-way ANOVA followed by individual Man$\mathrm{n}$-Whitney $U$ test was used. Statistical analysis of cell counting and immunoblot quantifica-
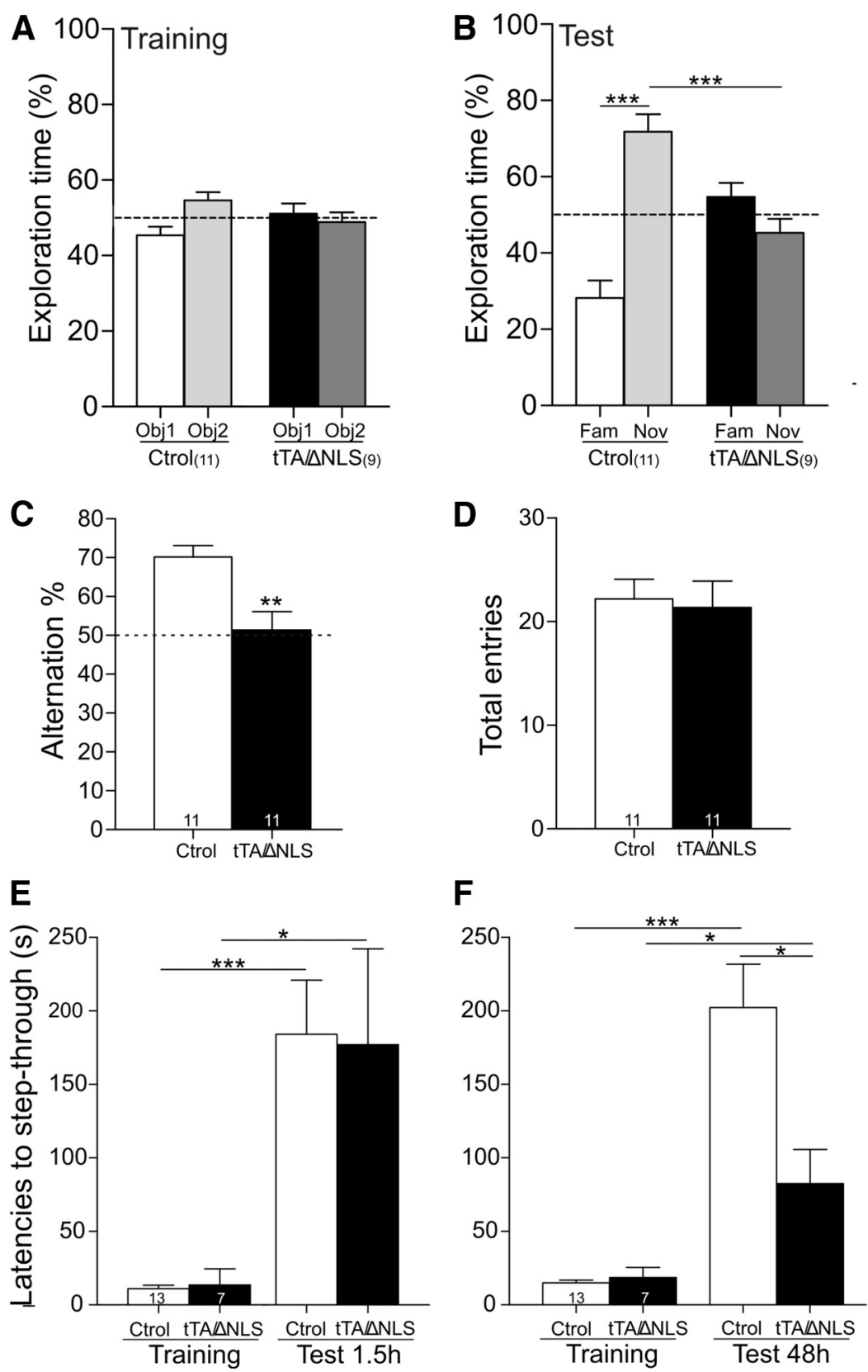

Figure 3. Cognitive deficits in TDP-43- $\Delta$ NLS transgenic mice. $\boldsymbol{A}, \boldsymbol{B}$, Novel object recognition test. $\boldsymbol{A}$, Training day. Mice were exposed to two identical objects placed at opposite ends of the arena for $10 \mathrm{~min}$ and the time spent exploring each object was recorded. There was no difference in object exploration of the two objects in the training phase. $\boldsymbol{B}$, Twenty-four hours later (test day), the mice were allowed to explore 1 copy of the previously presented object (familiar) and a new object (novel) for $5 \mathrm{~min}$. The exploration time (\%) represents the percentage of time that mice spend exploring the object (familiar or novel) respect to the total exploration time (familiar + novel). tTA/ $\Delta$ NLS animals displayed no evidence of object recognition memory ( ${ }^{* *} p<0.001$, one-way ANOVA/Newman-Keuls post hoc test). C, D, Y-maze spontaneous alternation task. Mice were placed at the end of one arm facing the center and allowed to explore the maze freely for $8 \mathrm{~min}$ without training, reward, or punishment. Entries into each arm were scored and alternation behavior was defined as a complete cycle of consecutive entrances into each of the 3 arms without repetition. $C, t T A / \Delta N L S$ mice alternated between the arms at the chance level $\left({ }^{* *} p<0.01\right.$ significantly different from (trol group Student's $t$ test). $\boldsymbol{D}$, Total entries were scored as an index of ambulatory activity in the $Y$ maze. Cognitive behavior was analyzed at 1 month off Dox. $\boldsymbol{E}, \boldsymbol{F}$, Inhibitory avoidance task. During training, each mouse received a footshock as it stepped into the dark compartment $(0.8 \mathrm{~mA}, 50 \mathrm{~Hz}$, $1 \mathrm{~s})$. Retention test was performed $1.5 \mathrm{~h}$ (short-term memory) or $48 \mathrm{~h}$ (long-term memory) later. The step-through latency was recorded; footshock was omitted during test session. $\boldsymbol{E}$, Bigenic mice showed intact short-term memory compared with control littermates. $\boldsymbol{F}$, TDP-43- $\Delta$ NLS mice had significantly lower step-through latencies $48 \mathrm{~h}$ after training, indicating a deficit in long-term memory. $\left({ }^{*} p<0.05 ;{ }^{* * *} p<0.001\right.$ Kruskal-Wallis one-way ANOVA followed by individual MannWhitney $U$ test). Number of animals is indicated in parentheses or inside plot bars. Data represent mean \pm SEM. 
tions was performed using one-way ANOVA followed by NewmanKeuls multiple-comparison post hoc tests. Prism 6 (GraphPad) or SPSS version 17 software were used for statistical analysis and differences were considered to be statistically significant when $p<0.05$.

\section{Results}

Postweaning TDP-43- $\Delta$ NLS overexpression in forebrain neurons leads to motor abnormalities

In this study, we used previously generated mutant TDP-43$\Delta$ NLS Tg mice with a tet-off system and the CaMKII $\alpha$ promoter to model human TDP-43 proteinopathies (Igaz et al., 2011). Tg expression was induced at weaning and animals were analyzed at different times after Dox removal (Fig. 1A). The body weight curve of these mice was indistinguishable from control littermates up to 2 weeks after induction. Beyond this point, bigenic mice were slightly (13-18\%) but significantly smaller, although the growth curve slope was similar (two-way ANOVA, $F_{(1,182)}=$ $20.89, p<0.0001$ for group; $F_{(5,182)}=84.10, p<0.0001$ for time of induction; $F_{(5,182)}=3.774, p=0.0028$ for interaction; Fig. $\left.1 B\right)$. To avoid the dilution effect of nonexpressing structures such as cerebellum, we next analyzed the weight of two forebrain structures that highly express the Tg. Cortical and hippocampal tissue weights from TDP-43- $\Delta$ NLS Tg mice were significantly lower than age-matched controls at the 6 month, but not at the 1 month, time point off of Dox (Fig. $1 C, D$ ), indicating timedependent atrophy of these brain areas. The physical appearance of Tg mice revealed no visible problems (including abnormal growth, posture, and gait) that could potentially interfere with behavioral testing. The righting reflex was normal in Tg mice and we found no deficits in visual function as assessed by visual placing and visual cliff tests (Fig. $1 E$ ). No evidence of muscle atrophy was previously found as analyzed by $\mathrm{H} \& \mathrm{E}$ staining of forelimb and hindlimb striated muscles (Igaz et al., 2011). All behavioral tests were conducted at 1 month after induction unless otherwise stated.

Most transgenic mice based on TDP-43 manipulation use pan-neuronal promoters that usually lead to rapid onset of "swimming" gait and paralysis related to lower motor neuron degeneration and, in some cases, eventually death (Tsao et al., 2012). We reasoned that inducible and forebrain-enriched TDP43- $\Delta$ NLS expression, sparing lower motor neuron Tg expression and subsequent degeneration (Igaz et al., 2011), would help to circumvent early symptoms that would make it impossible to properly test or interpret other domains of animal behavior. Because this is a novel Tg model that has been previously characterized at the neuropathological level and at the global gene expression pattern level, we first wanted to address the impact of TDP-43- $\Delta$ NLS expression on motor function. Tg mice were subjected to two variants of the rotarod test, a fixed speed version and an accelerated version (Fig. $2 A, B$ ), and the results indicated that they were drastically impaired in motor coordination and balance (repeated-measures ANOVA, $F_{(1,54)}=62.49, p<0.0001$ for group; $F_{(3,54)}=19.06, p<0.0001$ for trial; $F_{(3,54)}=4.869, p=$ 0.0045 for interaction; Fig. $2 B$ ). In addition, TDP-43- $\Delta$ NLS mice displayed a reduction in latency to fall in a hang wire test, suggesting a mild decrease in grip strength (Fig. 2C). To measure general motor function and exploratory activity, we used an open field test. TDP-43- $\Delta$ NLS Tg animals displayed severe hyperlocomotion and reduced relative center distance (Fig. 2D,E). More detailed analysis of distance traveled by time bins indicated that, during the first $5 \mathrm{~min}$, locomotor activity did not differ significantly from control mice, but was dramatically increased during the rest of the open field test duration (repeated-measures
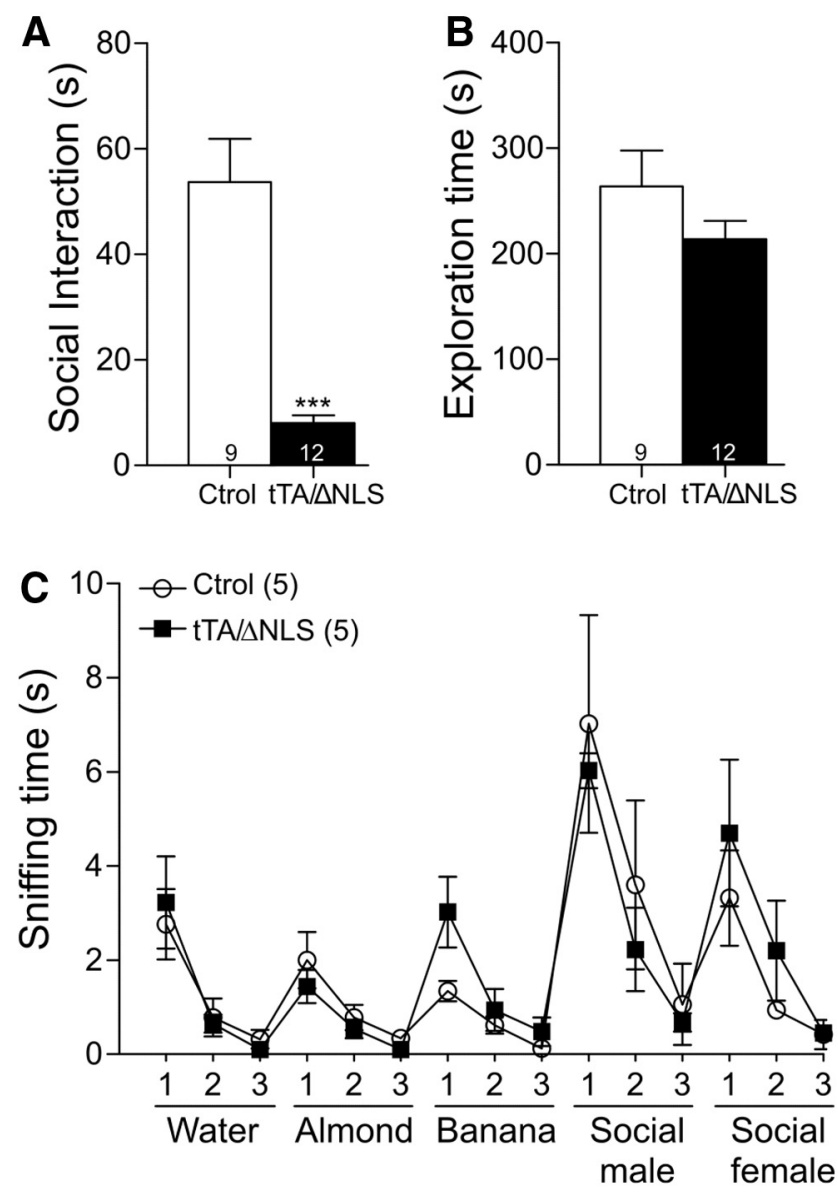

Figure 4. TDP-43- $\Delta$ NLS mice display abnormalities in social behavior. $\boldsymbol{A}, \boldsymbol{B}$, Social interaction test. $A$, Time spent sniffing the social (P21-P28 mouse) stimulus (social interaction) during a 10 min session. 1 month off Dox bigenic mice presented a reduced social interaction time during the session ( ${ }^{* * *} p<0.001$ significantly different from (trol group, Student's $t$ test). $\boldsymbol{B}$, No difference between groups was found in exploration time of the social chamber. C, Olfactory habituation/dishabituation test, 1 month off Dox. Swabs were dipped in tap water, almond extract (1:300), banana extract (1:300), and the bottom surface of a plastic cage that contained either a group of male or female mice. A 2 min odor presentation was used. There are no significant differences between groups (repeated-measures ANOVA/Bonferroni post hoc test). Number of animals is indicated in parentheses or inside plot bars. The data are displayed as mean \pm SEM

ANOVA, $F_{(1,84)}=36.94, p<0.0001$ for group; $F_{(3,84)}=13.26$, $p<0.0001$ for time bin; $F_{(3,84)}=23.01, p<0.0001$ for interaction; Fig. $2 F$ ). Last, we performed a time course analysis of limbclasping reflex phenotype. Although control animals extended their limbs normally when being suspended by their tails, by 1 month of induction, all of the Tg mice and none of the controls displayed this altered response (Fig. 2G). Together, these data demonstrate that TDP-43- $\Delta$ NLS mice display early motor abnormalities at 1 month after Tg induction.

\section{TDP-43- $\Delta$ NLS mice develop cognitive deficits}

Cytoplasmic TDP-43 expression is a hallmark of FTLD-TDP proteinopathy (Neumann et al., 2006), and both in vitro and in vivo studies in Drosophila and mammalian models showed that TDP-43 mislocalization might lead to TDP-43 sequestration, toxicity, and motor impairment (Winton et al., 2008; Miguel et al., 2011; Dayton et al., 2013). Although TDP-43 has been indicated as a neuronal activity-related factor (Wang et al., 2008), there is no clear evidence for the role of cytoplasmic TDP-43 in memory and cognition. To determine whether restricted TDP- 

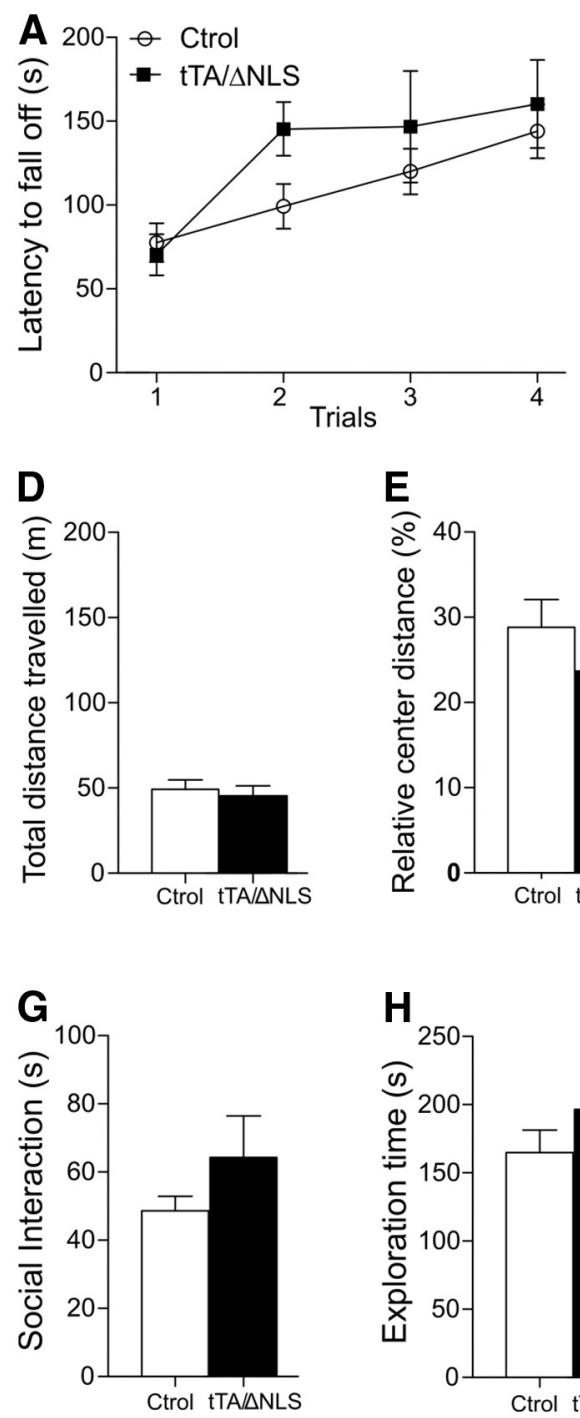

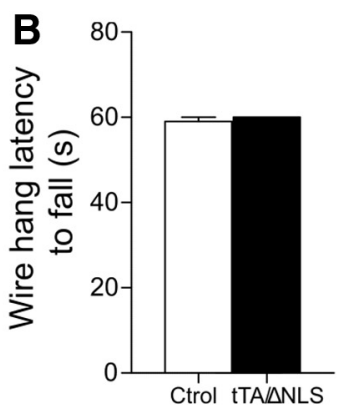

C

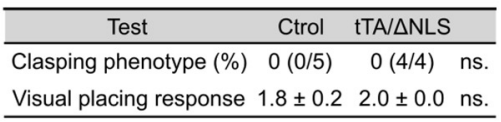

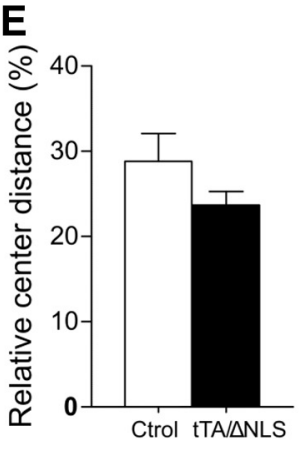

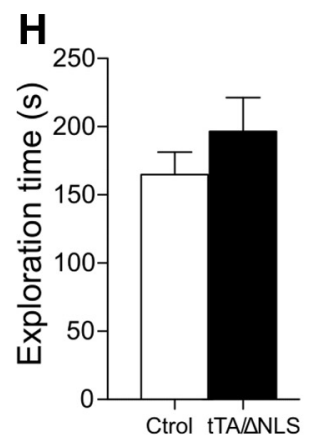

$\mathbf{F}$
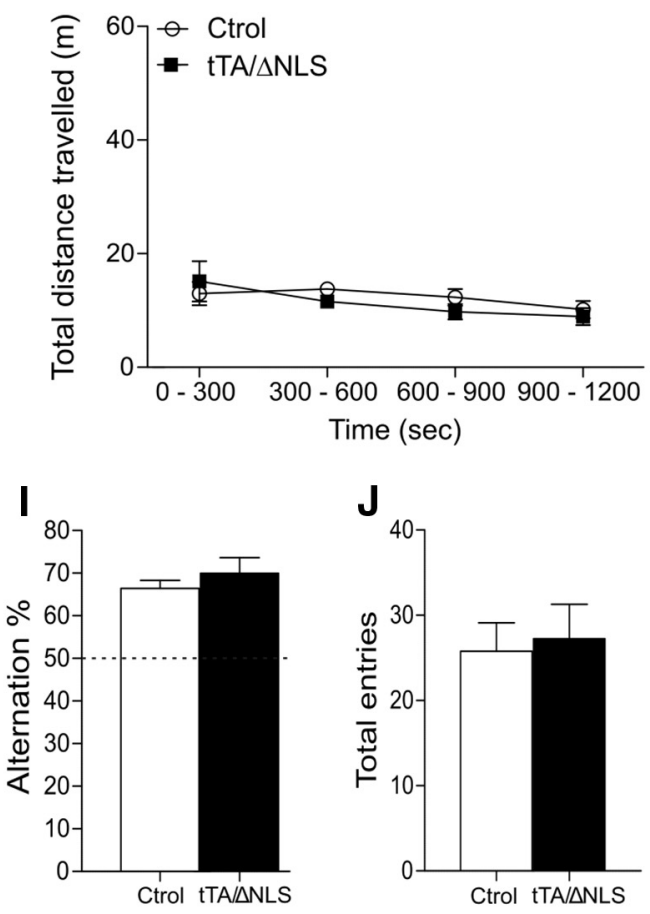

Figure 5. Assessment of motor, visual, social, and cognitive behavior in control and bigenic mice raised continuously on Dox until 1 month after weaning. $A$, Accelerated rotarod test. $\boldsymbol{B}$, Hanging wire grip test. $\boldsymbol{C}$, Limb-clasping motor phenotype and visual placing response test. $\boldsymbol{D}-\boldsymbol{F}$, Exploratory and locomotor activity in the open field test. $\boldsymbol{D}$, Total distance traveled in the open field chamber. $\boldsymbol{E}$, Relative center distance during the open field session. $\boldsymbol{F}$, Open field time bin analysis. $\boldsymbol{G}, \boldsymbol{H}$, Social interaction test. $\boldsymbol{G}$, Time spent sniffing the social stimulus during a 10 min session. $\boldsymbol{H}$, Exploration time of the social chamber. $I, J$, Y-maze alternation task. $I$, Percentage of spontaneous alternation during an 8 min session. $J$, Total entries scored. No differences between control and bigenic groups were found in the behavioral analysis ( $\boldsymbol{A}$ and $\boldsymbol{F}$ : repeated-measures ANOVA, $F_{(1,18)}=1.177, p=0.3196$ for group in $\boldsymbol{A}$ and $F_{(1,21)}=0.2129, p=0.6585$ for group in $\boldsymbol{F} ; \boldsymbol{B}, \boldsymbol{D}, \boldsymbol{E}, \mathbf{G}-\boldsymbol{J}: p>0.05$, Student's $t$ test; $C: p>0.05$, Mann-Whitney test). Data represent mean \pm SEM (Ctrol, $n=5 ; \mathrm{tTA} / \Delta \mathrm{NLS}, n=4)$.

43- $\Delta$ NLS expression leads to cognitive dysfunction, we used the novel object recognition task, which is heavily dependent on cortical function and takes advantage of a rodent's innate preference for novel over familiar objects. During the training day, both control and bigenic mice did not show a preference for any of two identical objects (Fig. 3A). Twenty-four hours later (test day), mice were presented with the same (familiar) object and a novel object and exploration time was measured. Although control animals clearly displayed the expected novel object preference, TDP-43- $\Delta$ NLS mice showed no preference at all, demonstrating impaired recognition memory (one-way ANOVA, $F_{(3,34)}=$ $20.21, p<0.0001$; Fig. $3 B$ ). We further evaluated the cognitive performance by using other memory tests. To assess working memory, we used the Y-maze spontaneous alternation test, which depends on prefrontal cortex function and also on the hippocampus due to the spatial nature of the task. The Y-maze test relies on the animal's preference to investigate a new arm of the maze rather than returning to a previously visited arm (Bel- forte et al., 2010). We measured the percentage of spontaneous alternation and found that, whereas control mice avoided the previously visited arms, $\mathrm{Tg}$ mice alternated at chance (50\%) level, indicating impaired working memory (Fig. 3C). Importantly, the total number of arm entries was similar between groups (Fig. 3D).

To evaluate associative learning, we performed the inhibitory avoidance task, another cognitive test that has the additional advantage of being an associative, fear-motivated learning paradigm. During the training session, latency to step through a dark compartment was not different between 2-month off Dox control and Tg mice (Fig. 3E,F). Mice were given a footshock upon entrance to the dark chamber and tested $48 \mathrm{~h}$ later for inhibitory avoidance memory. Although control mice showed very high latency to enter the dark compartment (i.e., retained the memory for the aversive event), bigenic mice had significantly lower latencies, indicating a deficit in long-term memory for this task (Fig. $3 F)$. Importantly, a group of mice tested $1.5 \mathrm{~h}$ after training 

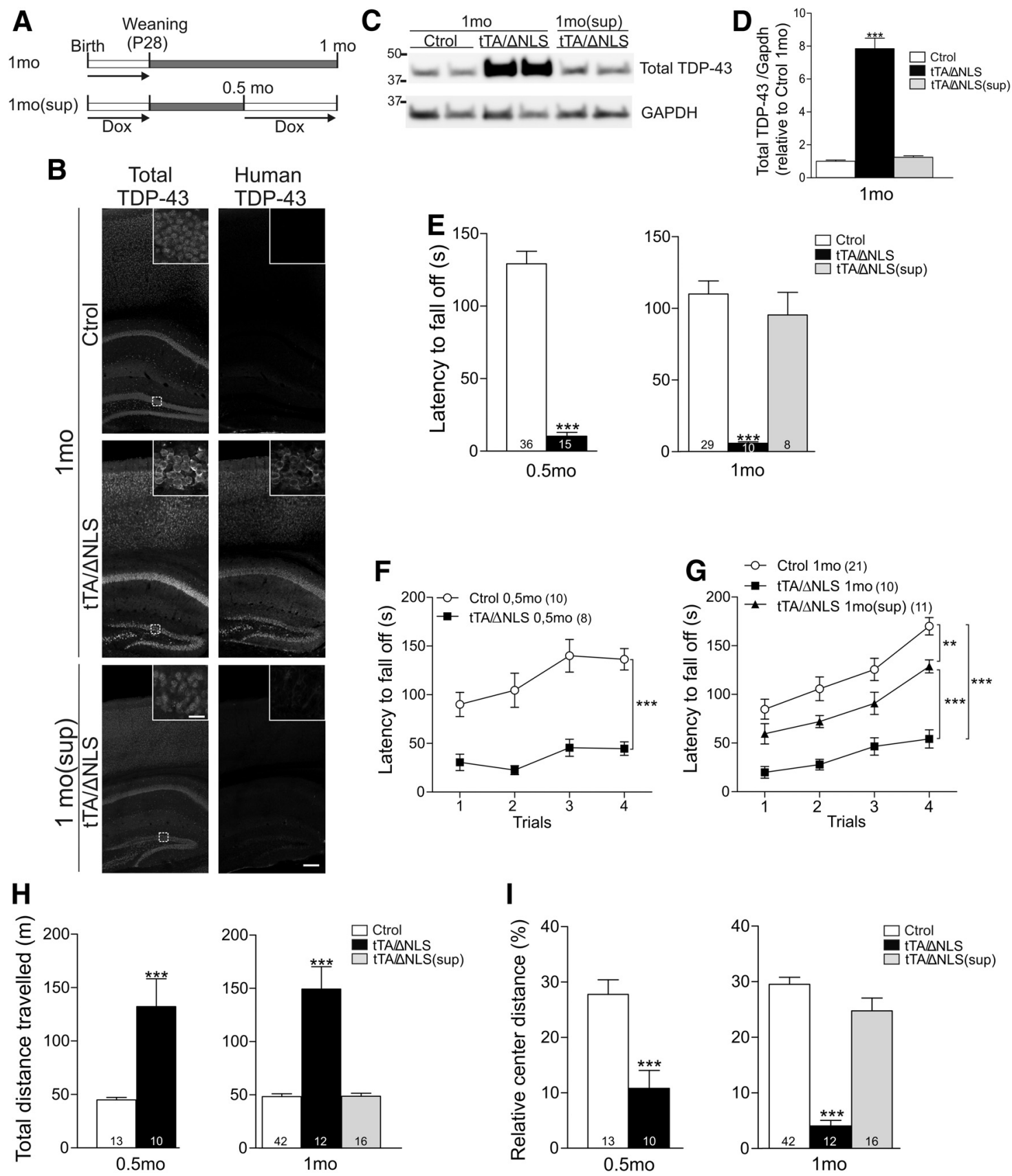

\section{I}

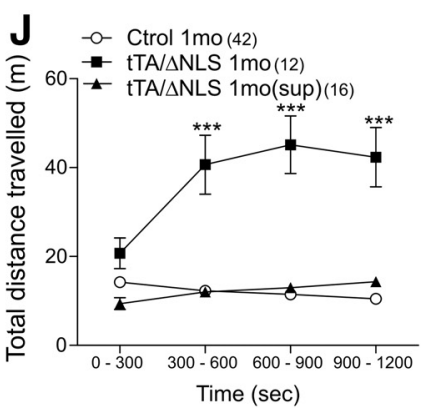

\section{K}

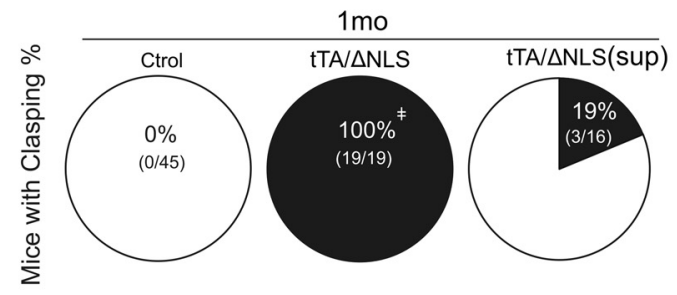

Figure 6. TDP-43- $\Delta$ NLS suppression reverses motoric phenotypes in young transgenic mice. $\boldsymbol{A}$, Experimental design. Mice raised on Dox until P28 were treated again with Dox at 0.5 months after weaning to suppress transgene expression during 2 weeks [1 mo(sup) mice] and analyzed 1 month after weaning. These mice were compared with mice in which transgene expression was maintained until 1 month after weaning (1mo mice, Ctrol and tTA/DNLS). B, Double immunofluorescence for total TDP-43 and hTDP-43 in coronal brain sections from $1 \mathrm{mo}$ (Ctrol and tTA/ $\Delta$ NLS) and 1mo(sup) mice. Scale bar, $250 \mu \mathrm{m}$; inset, $20 \mu \mathrm{m}$. C, Immunoblot of total TDP-43 (h+mTDP-43) in cortical RIPA extracts. GAPDH was used as a loading control. D, Quantification of the immunoblot shown in $\boldsymbol{C}\left({ }^{* * *} p<0.001\right.$, one-way ANOVA/Newman-Keuls post hoc test, $n=4$ per group). $\boldsymbol{E}-\boldsymbol{K}$, Assessment of general motor behavior was performed in 0.5 mo, 1 mo, and 1 mo(sup) mice. $\boldsymbol{E}$, Fixed speed rotarod test. $\boldsymbol{F}, \mathbf{G}$, Accelerated rotarod test. $\boldsymbol{H}$, Total distance traveled in the open field chamber. $\boldsymbol{I}$, Relative center distance during the open field session. $\boldsymbol{J}, 0$ pen field time bin analysis. $\boldsymbol{K}$, Abnormal limb-clasping motor phenotype. 0.5 mo bigenic mice already displayed an altered motor behavior compared with $($ trol littermates ( $\boldsymbol{E}, \boldsymbol{H}, \boldsymbol{I}$, left; $\boldsymbol{F})$. Remarkably, (Figure legend continues.) 
showed no significant decrease in latency compared with controls (Fig. $3 E$ ), demonstrating that TDP-43- $\Delta$ NLS mice can acquire the task and have intact short-term memory but cannot consolidate it into a long-lasting memory. These results indicate that neuronal TDP-43- $\Delta$ NLS overexpression in forebrain regions impaired cognitive function as assessed by multiple behavioral tasks.

\section{Social dysfunction in TDP-43- $\Delta$ NLS mice}

Although cognitive and motor symptoms occur to different degrees within the FTD spectrum, patients affected with this disease display other types of behavioral deficits. A core feature of FTD is repetitive behavior, which is useful for the revised diagnostic criteria and is present in most FTD patients. In mice, this commonly takes the form of excessive grooming and other stereotypies. We studied the occurrence of spontaneous grooming in control and TDP-43- $\Delta$ NLS bigenic mice and found no significant differences in total grooming time $(71.37 \pm 12.53 \mathrm{~s}$ vs $55.95 \pm 10.01 \mathrm{~s}$ for control and TDP-43- $\Delta$ NLS mice, respectively; $t_{(18)}=0.9617, p=$ 0.3489 ).

One of the earliest and most prominent symptoms of FTD is social dysfunction, which can be expressed as diminished social interest. We tested the social behavior of TDP-43- $\Delta$ NLS mice at 1 month after induction using a 3-chamber social interaction test (Moy et al., 2004). As expected, control mice spent more time interacting with the other mouse (social stimulus) than with the inanimate object (nonsocial stimulus). However, TDP-43- $\mathrm{N}$ NSS expressing mice showed drastically reduced sociability, because the preference for the social stimulus was significantly lower than in control animals (Fig. 4A). Exploration time in the social side was similar between groups, indicating that this decrease in social interaction time is not due to increased anxiety-like behavior or perception of the stimulus as aversive (Fig. $4 B$ ). Because the performance in this test depends critically in proper olfaction and the CaMKII $\alpha$ promoter drives Tg expression in the olfactory bulb, we also tested olfactory performance using a habituation/dishabituation test. Bigenic mice did not display significant differences in performance for both nonsocial and social odoriferous stimuli, suggesting intact olfactory function (repeated-measures ANOVA, $F_{(1,112)}=0.02245, p=0.8846$ for group; $F_{(14,112)}=14.77, p<$ 0.0001 for odorant; Fig. $4 C$ ). These results show that TDP-43- $\Delta$ NLS mice exhibit an altered social behavior.

A potential contributor for the behavioral abnormalities observed in TDP-43- $\Delta$ NLS mice is a possible insertional effect of the $\mathrm{Tg}$ in the genome. To rule out this possibility, we performed a variety of tests encompassing all the previously assessed behavioral domains in bigenic animals continuously treated with Dox throughout the experiment. Importantly, these animals with 2 months of constant suppression of TDP-43- $\mathrm{NLS}$ expression showed responses indistinguishable from control mice in all parameters evaluated (Fig. 5).

\footnotetext{
(Figure legend continued.) $1 \mathrm{mo}$ (sup) mice recover from motoric abnormalities $(\boldsymbol{E}, \boldsymbol{H}, \boldsymbol{I}$, right; $\boldsymbol{G}$, $J, K)$. $\left(E, H, I\right.$, left: ${ }^{* *} p<0.001$ significantly different from Ctrol group, Student's $t$ test; $\boldsymbol{E}, \boldsymbol{H}, \boldsymbol{I}$, right: ${ }^{* * *} p<0.001$, one-way ANOVA/Newman-Keuls post hoctest; $\boldsymbol{F}, \boldsymbol{G}^{* *} p=0.007 ;{ }^{* * *} p<$ 0.001 repeated-measures ANOVA/Bonferroni post hoc analysis; $J^{* * *} p<0.001$ significantly different from $1 \mathrm{mo}$ Ctrol and $1 \mathrm{mo}($ sup) (repeated measures ANOVA/Bonferroni post hoc analysis). $\boldsymbol{K}, 1 \mathrm{mo}$ tTA/ $\Delta \mathrm{NLS}$ differs significantly from $1 \mathrm{mo}$ Ctrol and $1 \mathrm{mo}$ (sup) tTA/ $\Delta \mathrm{NLS}$ ( $\neq p<$ 0.001 , Kruskal-Wallis one-way ANOVA/Mann-Whitney Utest). Number of animals is indicated in parentheses or inside plot bars. Data represent mean \pm SEM.
}

\section{Suppression of TDP-43- $\Delta$ NLS Tg reverses motor deficits in young mice}

Currently, there are no effective disease-modifying therapies for TDP-43 proteinopathies. It is basically unknown whether targeting TDP-43 can inhibit neurodegeneration and reverse behavioral abnormalities. Having established that TDP-43- $\Delta$ NLS mice exhibit a neurological phenotype, we were interested in determining whether turning off the TDP- $43 \mathrm{Tg}$ would ameliorate the symptoms in phenotypic mice. First, we defined a time point of interest ( 1 month after induction) and then decided to treat mice with Dox 2 weeks before that point to suppress TDP-43- $\Delta$ NLS expression (Fig. 6A). We chose 2 weeks off Dox as a starting point because we previously demonstrated global changes in cortical gene expression seemingly without overt general neurodegeneration at that specific postinduction time. In addition, TDP-43$\Delta$ NLS expression is almost maximal starting at 1 week after induction (Igaz et al., 2011). Both control and bigenic mice were separated into two subgroups (with and without Dox treatment), but we decided to pool Dox-treated and untreated control groups after the analysis because they were indistinguishable in all parameters evaluated. Bigenic mice with and without Dox treatment were analyzed separately. To assess proper regulation of $\mathrm{Tg}$ expression, we performed double immunofluorescence studies using a polyclonal antibody (referred as total TDP-43) that reacts to both endogenous (mouse) and Tg (human) forms of TDP-43 and a monoclonal antibody that only recognizes the human isoform of the TDP-43 protein (in this case, TDP-43- $\Delta \mathrm{NLS}$ ), termed hTDP-43. Representative micrographs show that mice from the $1 \mathrm{mo}$ (sup) group are almost completely devoided of hTDP-43 immunoreactivity (Fig. 6B). Immunoblot analysis of cortical RIPA fractions extracted from the other hemisphere of the same experimental mice (Fig. $6 \mathrm{C}$ ) confirmed Tg expression reduction to basal levels in the suppressed group (one-way ANOVA, $F_{(2,9)}=105.5, p<0.0001$; Fig. $\left.6 D\right)$, and similar levels to those previously reported in bigenic mice 1 month after induction (Igaz et al., 2011).

Although we established that bigenic mice display a motor phenotype 1 month after induction (Fig. 2), we wanted to determine whether the behavioral abnormalities were already present at the starting time point of suppression ( 0.5 month induction). In this way, we could differentiate between prevention and reversion of the phenotype by Tg suppression. Behavioral analysis at 0.5 months after induction revealed significant deficits in bigenic mice for both the fixed (Fig. $6 E$, left) and accelerated rotarod tests (repeated-measures ANOVA, $F_{(1,48)}=29.70, p<0.0001$ for group; $F_{(3,48)}=9.931, p<0.0001$ for trial; $F_{(3,48)}=2.110, p=$ 0.1113 for interaction; Fig. $6 F$ ). Remarkably, ANOVA followed by post hoc analysis showed that animals from the $1 \mathrm{mo}(\mathrm{sup})$ group recovered, displaying nonsignificant differences compared with control mice in the fixed speed test (one-way ANOVA, $F_{(2,36)}=22.96, p<0.0001$; Fig. $6 E$, right). In the accelerated rotarod test, suppressed animals displayed a significant reversion of the phenotype, although they did not reach the performance level of controls (repeated-measures ANOVA, $F_{(2,117)}=31.79$, $p<0.0001$ for group; $F_{(3,117)}=24.86, p<0.0001$ for trial; $F_{(6,117)}=$ $1.461, p=0.1977$ for interaction; Fig. $6 G)$. When we performed a similar analysis in the open field test, the results showed that $\mathrm{Tg}$ suppression fully reversed an established motor phenotype (oneway ANOVA, $F_{(2,67)}=46.87, p<0.0001$ and $F_{(2,68)}=51.23, p<$ 0.0001 for Fig. $6 H$, right, Fig. 6I, right, respectively; repeatedmeasures ANOVA, $F_{(2,201)}=46.29, p<0.0001$ for group; $F_{(3,201)}=$ 29.41, $p<0.0001$ for time bin; $F_{(6,201)}=28.02, p<0.0001$ for interaction; Fig. $6 J$ ). Last, we evaluated the clasping reflex and 
A
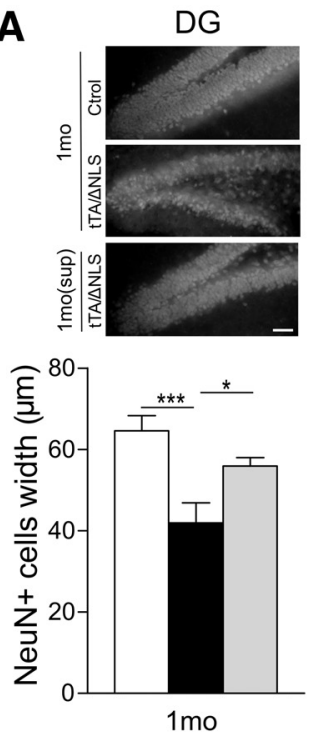

D

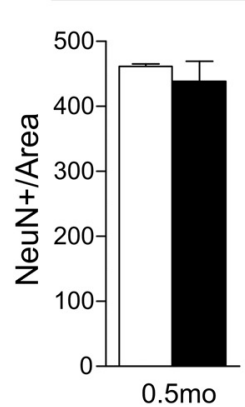

SSC

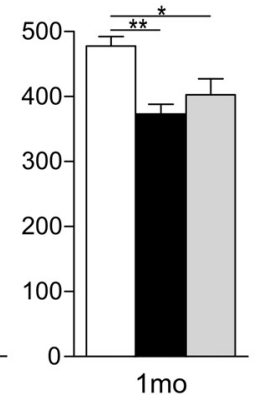

B
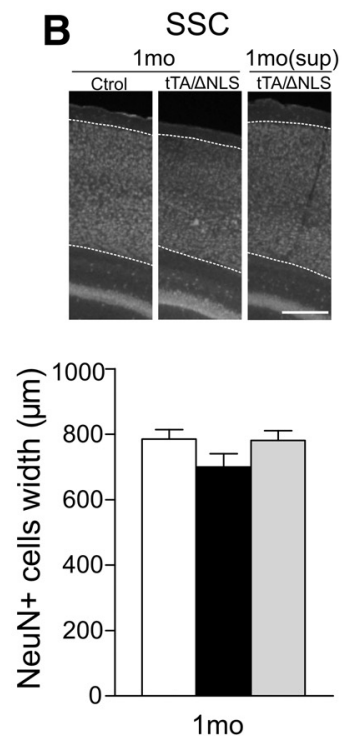

E

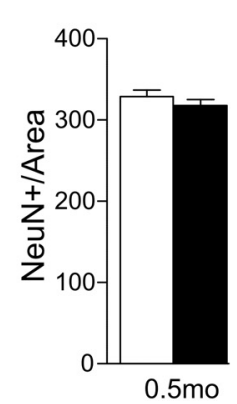

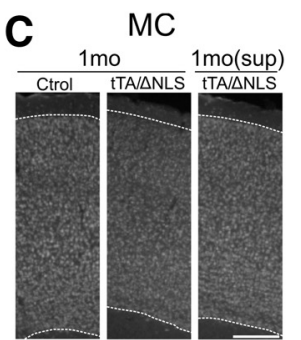

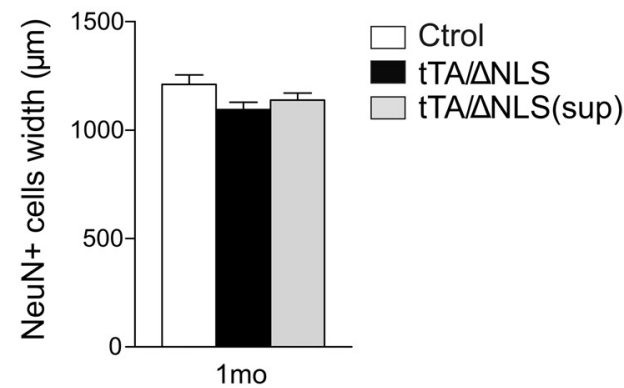

$\mathbf{F}$

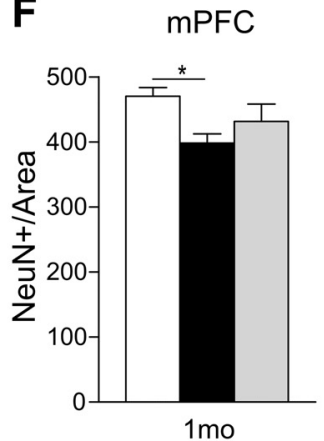

Figure 7. Mild neurodegeneration in young TDP-43- $\Delta \mathrm{NLS}$ transgenic mice. $\boldsymbol{A}-\boldsymbol{C}$, Immunofluorescence staining for the neuronal marker NeuN in coronal brain sections (top) and thickness measurements (bottom) from DG granule cell layer $(\boldsymbol{A}), \mathrm{SSC}(\boldsymbol{B})$, and $\mathrm{MC}(\boldsymbol{C})$ from $1 \mathrm{mo}(\mathrm{trol}, \mathrm{tTA} / \Delta \mathrm{NLS}$, and tTA/ $\Delta \mathrm{NLS}$ (sup) mice. DG thickness was significantly reduced in tTA/ $\Delta \mathrm{NLS}$ with respect to Ctrol mice. Scale bars: $\boldsymbol{A}, 50 \mu \mathrm{m} ; \boldsymbol{B}$ and $\boldsymbol{C}, 250 \mu \mathrm{m}$. D-F, Quantification of NeuN-positive cells in cortical regions (layer 5). SSC (D), MC (E), and PFC (F). 1 mo tTA/ $\Delta$ NLS mice showed significant neuronal loss in the SSC, MC, and mPFC regions. Data are presented as total NeuN-positive cells per area ( ${ }^{*} p<0.05 ;{ }^{* *} p<0.01 ;{ }^{* * *} p<0.001$ one-way ANOVA/Newman-Keuls posthoc test). Data represent mean $\pm \operatorname{SEM}(n=8-10$ per group).

also observed a significant recovery of performance in suppressed animals (Kruskal-Wallis statistic $=63.14, p<0.0001$; Fig. $6 K$ ). Together, these data demonstrate that short-term suppression of Tg expression can fully recover motoric abnormalities in young TDP-43- $\Delta$ NLS mice.

\section{Short-term TDP-43- $\Delta$ NLS expression leads to mild neurodegeneration in young mice}

An important question that arises from the behavioral experiments in suppressed mice is whether those deficits strongly correlate with neurodegeneration in regions relevant for the affected tasks or if they are caused by changes in neuronal function in TDP-43- $\Delta$ NLS-expressing cells without major neuronal loss in implicated circuits. To address this issue, we evaluated gross atrophy and neuronal loss in selected brain areas by immunostaining with NeuN, a marker of mature neurons. Total tissue weight suggested that, at 1 month after induction, there was no major neuronal loss (Fig. 1C,D), but measurements of overall weight of a brain structure cannot discriminate between neurodegeneration in different subfields or regions. We performed a series of thickness measurements of somatosensory (SSC) and motor cortex (MC), as well as of the granule cell layer (GCL) of hippocampal dentate gyrus (DG). We confirmed and expanded our observation that granule cells in the DG were very susceptible to
TDP-43- $\Delta$ NLS-associated degeneration in these mice (Fig. $7 A$ ) (Igaz et al., 2011). GCL thickness was significantly reduced in $\mathrm{tTA} / \Delta$ NLS mice compared with control mice (one-way ANOVA, $F_{(2,22)}=9.064, p=0.0013$; Fig. $7 A$ ). Interestingly, $1 \mathrm{mo}$ (sup) mice showed a significant increase with respect to the 1 mo group, but also a significant decrease with respect to control mice, suggesting an intermediate phenotype and a very rapid onset of granule cell loss. Cortical thickness from SSC and MC in both 1 month off Dox and 1mo(sup) mice was not significantly different from the control group (Fig. $7 B, C$ ).

To determine whether there were signs of incipient neuronal loss in cortical regions, we examined them in greater detail by counting the number of NeuN-positive cells. Given that brains from both FTD and TDP-43 murine models (including TDP-43$\Delta$ NLS mice) display increased ubiquitinated aggregates, reactive gliosis, and neurodegeneration in layer 5 (Seeley, 2008; Wegorzewska et al., 2009; Igaz et al., 2011), we focused our analysis on this layer. We detected no significant changes in SSC or MC neuronal numbers at 0.5 months after induction (Fig. $7 \mathrm{D}$, E, left). At 1 month after induction, there was a mild but significant decrease in SSC neuronal counts, similar to those presented by $1 \mathrm{mo}$ tTA $/ \Delta$ NLS(sup) bigenic animals (one-way ANOVA, $F_{(2,13)}=$ 9.069, $p=0.00343$; Fig. $7 D$ ). MC and prefrontal cortex (PFC) neuronal numbers from the $1 \mathrm{mo}$ group also showed a significant 

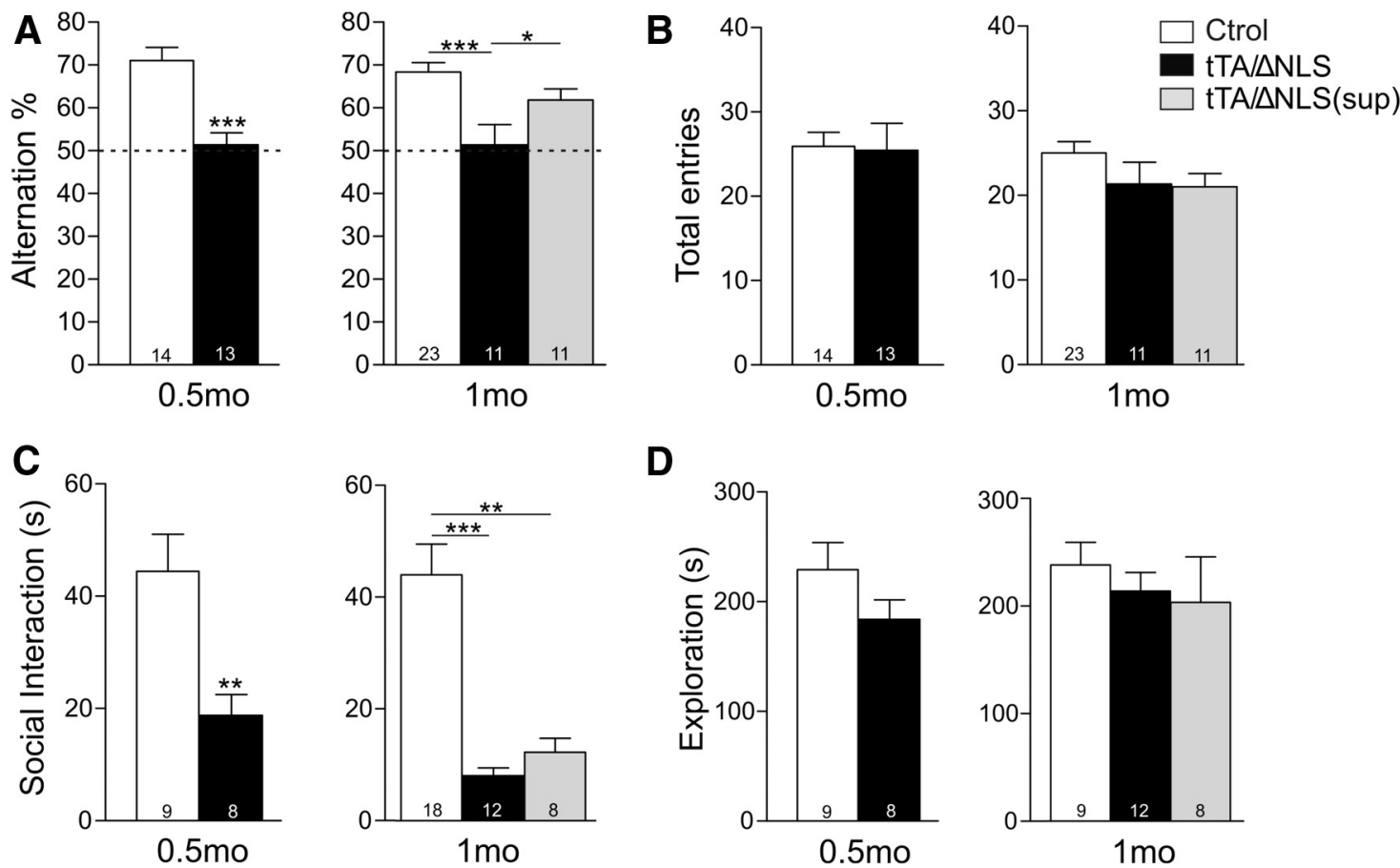

Figure 8. Reversal of cognitive but not social abnormalities in young bigenic mice after suppression of TDP-43- $\Delta$ NLS expression. Assessment of cognitive and social behavior was performed in

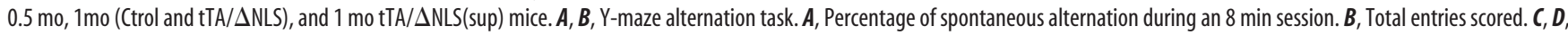
Social interaction test. $\boldsymbol{C}$, Time spent sniffing the social stimulus during a 10 min session. $\boldsymbol{D}$, Exploration time of the social chamber. Cognitive and social interaction dysfunction was already detectable at $0.5 \mathrm{mo}$ off $\operatorname{Dox}\left(A, C\right.$, left; ${ }^{* *} p<0.01,{ }^{* * *} p<0.001$ significantly different from Ctrol group, Student's t test). hTDP-43- $\Delta$ NLS suppression was able to rescue cognitive abnormalities, but did not cause any improvement in social interaction $\left(A, C\right.$, right; ${ }^{*} p<0.05$; ${ }^{* *} p<0.01$; ${ }^{* * *} p<0.001$, one-way ANOVA/Newman-Keuls post hoc test). Number of animals is indicated inside plot bars. Data represent mean \pm SEM.

decrease in bigenic animals relative to controls; this was not observed in the $1 \mathrm{mo}$ (sup) mice (one-way ANOVA, $F_{(2,25)}=4.438$, $p=0.0224$; Fig. $7 E$, right, $F_{(2,18)}=3.566, p=0.0496$; Fig. $\left.7 F\right)$. The variable response in neuronal loss observed in the suppressed group indicates that different regions are differentially susceptible to the manipulation.

NeuN relocalization to the cytoplasm can be used as an indicator of neuronal injury (Robertson et al., 2006; Aviles-Reyes et al., 2010). Although control mice display basically no cortical neurons with altered NeuN localization, 1 month off Dox bigenic mice showed an increase in injured SSC neurons, which was reversed with Tg suppression. A similar trend was observed in MC and PFC, although less markedly (data not shown). These data suggest that Dox treatment halts neurodegeneration, increasing the proportion of surviving and decreasing the number of injured neurons and thus incrementing the number of functionally active units in the remaining circuits necessary for the affected behaviors.

\section{Suppression of TDP-43- $\Delta$ NLS expression in young mice} ameliorates cognitive but not social abnormalities Because different behavioral domains might be differentially affected by arresting Tg expression, we also investigated whether Dox treatment could reverse other phenotypic changes in addition to motor performance. We assessed whether cognitive dysfunction was already detectable at the beginning of the suppression ( 0.5 months off Dox) using the Y-maze test and found that bigenic mice alternate at chance levels (Fig. 8A, left). Remarkably, Dox treatment was able to rescue spatial working memory (one-way ANOVA, $F_{(2,42)}=7.894, p=0.0012$; Fig. $8 A$, right). Total entry number was similar in all groups (one-way
ANOVA, $F_{(2,42)}=1.787, p=0.3304$; Fig. $8 B$, right). When we analyzed the social behavior, deficits were already present at 0.5 months off Dox, although to a lesser extent than 1-monthinduced mice (Fig. 8C, left). Tg suppression did not cause any improvement in social interaction (one-way ANOVA, $F_{(2,35)}=$ 19.84, $p<0.0001$; Fig. $8 C$, right) and, importantly, exploration time was equivalent among experimental groups (one-way ANOVA, $F_{(2,35)}=0.4996, p=0.6118$; Fig. $\left.8 D\right)$. These results indicate that most behavioral phenotypes develop quite rapidly after Tg induction; however, neural circuits subserving diverse behavioral domains are differentially affected by TDP-43- $\Delta$ NLS at this early time point.

\section{Persistence of motor deficits in 6 months off Dox mice with TDP-43- $\Delta$ NLS suppression}

In many neurodegenerative disease models, it is generally assumed that once the behavioral abnormalities are established, the concurrent and progressive neurodegeneration that takes place is increasingly responsible for the associated behavioral phenotypes. Given that our model has a rapid onset of these deficits with relatively mild neuronal loss, we wanted to study the potential for reversibility in a domain that was impaired at early time points after Tg induction but was fully reversed by suppressing its expression. We first established a protocol for short-term suppression in older mice with 5.5 months of Tg expression (Fig. 9A). As shown for $1 \mathrm{mo}$ (sup) animals (Fig. 6B-D), mice with long-term Tg expression were effectively repressed by 2 weeks of Dox treatment, as evidenced by double immunofluorescence (Fig. $9 B$ ) and immunoblot studies (Fig. 9C) in $6 \mathrm{mo}(\sup )$ mice (one-way ANOVA, $F_{(2,8)}=18.19, p=0.0011$; Fig. 9D). Because motor performance was a behavioral parameter that recovered after $\mathrm{Tg}$ 

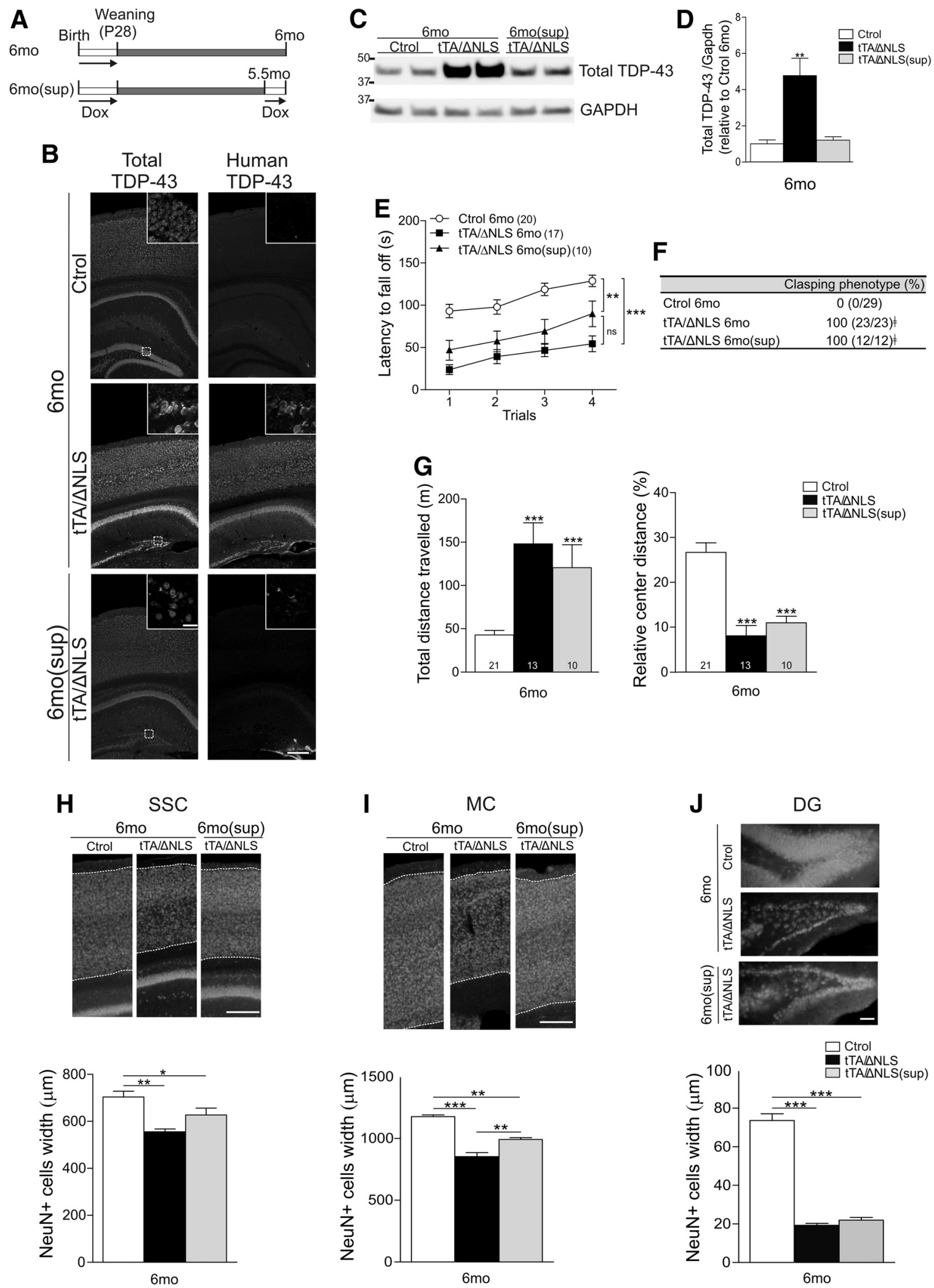

Figure 9. Transgene suppression in older ( 6 months off Dox) mice does not reverse motor abnormalities. A, Experimental design. Mice raised on Dox until P28 were treated again with Dox at 5.5 months after weaning to suppress transgene expression during 2 weeks (6mo(sup) mice) and analyzed at 6 months after weaning. These mice were compared with mice in which transgene expression was maintained until 6 months after weaning ( 6 mo mice, Ctrol, and tTA/ $\Delta N L S$ ). B, Double immunofluorescence for total TDP-43 (green) and hTDP-43 (red) in coronal brain sections from $6 \mathrm{mo}$ (Ctrol and tTA/ANLS) and 6mo(sup) mice. Scale bar, $250 \mu \mathrm{m}$; inset, $20 \mu \mathrm{m}$. C, Immunoblot of total TDP-43 (h+mTDP-43) in cortical RIPA extracts. GAPDH was used as a loading control. D, Quantification of the immunoblot shown in $\mathbf{C}\left({ }^{* *} p<0.01\right.$, one-way ANOVA/Newman-Keuls post hoc test, $n=3$ per group). $\boldsymbol{E}-\boldsymbol{G}$, Motor behavior analysis was performed in $6 \mathrm{mo}$ and $6 \mathrm{mo}$ (sup) mice. $\boldsymbol{E}$, Accelerated rotarod test. $\boldsymbol{F}$, Percentage of mice with abnormal limb-clasping motor phenotype. $\boldsymbol{G}$, Total distance traveled (left) and relative center distance (right) during an open field session. As expected, tTA/ $\Delta$ NLS 6 mo mice presented motor abnormalities in all the tests performed; however, hTDP-43- $\Delta$ NLS suppression was unable to rescue these behavioral abnormalities (E; ${ }^{* *} p=0.001 ;{ }^{* *} p<0.001$ significantly different; $\mathrm{ns}$, nonsignificant, $p=0.111$, repeated-measures ANOVA/Bonferroni post hoc analysis; $\mathbf{G}$; ${ }^{* *} p<0.001$, (Figure legend continues.) 
suppression in young mice, we assessed the animals in the accelerated rotarod test. As expected, 6 months off Dox bigenic mice performed poorly on this task but, contrary to what happened when younger mice were suppressed, Dox treatment failed to rescue their performance, because comparison of $6 \mathrm{mo}$ (sup) versus 6 mo mice reveals nonsignificant differences between these two groups (repeated-measures ANOVA, $F_{(2,44)}=25.90, p<$ 0.0001 for group; $F_{(3,44)}=21.98, p<0.0001$ for trial; $F_{(6,44)}=$ $0.6665, p=0.6768$ for interaction; Fig. $9 E)$. Similarly, full penetrance of the clasping abnormalities was not modified by $\mathrm{Tg}$ suppression (Kruskal-Wallis statistic $=63.00, p<0.0001$; Fig. $9 F)$. In the open field test, hyperlocomotion and decreased relative center distance were also manifest and insensitive to Dox treatment (one-way ANOVA, $F_{(2,41)}=12.24, p<0.0001$ for total distance traveled and $F_{(2,41)}=23.65, p<0.0001$ for relative center distance; Fig. $9 G$ ). Last, we assessed the degree of atrophy in relevant brain areas and found robust and widespread neuronal loss in SSC, MC, and DG, as indicated by decreased cortical and GCL thickness (one-way ANOVA, $F_{(2,9)}=$ 10.03, $p=0.0051$ for SSC, $F_{(2,9)}=52.37, p<0.0001$ for MC and $F_{(2,9)}=185.3, p<0.0001$ for DG; Fig. $\left.9 H-J\right)$. These data indicate that, once extensive neurodegeneration occurs, functional changes in the remaining neurons might not be sufficient to recover complex behaviors that require those affected networks.

\section{Discussion}

In this study, we performed a thorough behavioral assessment of TDP-43- $\Delta$ NLS mice and established that progressive neurodegeneration occurs in several affected brain areas. We took advantage of this inducible model to address the question of whether a neurological phenotype, once present in the mice, could be reversible after turning off $\mathrm{Tg}$ expression. In addition, the cellpopulation- and time-restricted expression of the $\mathrm{Tg}$ allowed us to dissect the contribution of forebrain neurons without the involvement and confounds of lower motor neuron expression and subsequent degeneration.

The major findings of our study are as follows. First, we showed that TDP-43- $\Delta$ NLS mice exhibited behavioral deficits related to TDP-43 proteinopathies, including motor impairment, reduced social interaction, and cognitive deficits (Figs. $2,3,4)$. Second, we found that after TDP-43 returned to normal levels, some (Figs. 6, 8) but not all (Fig. 8) behavioral deficits were ameliorated in young bigenic mice. The reversibility of the deficits after turning off TDP-43 overexpression suggests that the phenotypes in TDP-43- $\Delta$ NLS mice were mainly due to the Tg expression, not to insertional effects of the Tg into the genome. Third, our studies indicate that regional and time-dependent neurodegeneration occurs in these Tg mice, including areas relevant for the affected behavioral tasks (Figs. 7, 9). Fourth, we show that the same short-term suppression of Tg expression in older mice displaying more extensive neurodegeneration is not sufficient to improve behavioral performance (Fig. 9), indicating that a certain number of neurons must be preserved to compen-

$\leftarrow$

(Figure legend continued.) one-way ANOVA/Newman-Keuls post hoc test; $F$, $\neq p<0.001$ significantly different from $6 \mathrm{mo}$ Ctrol, Kruskal-Wallis one-way ANOVA followed by individual Mann-Whitney $U$ test). Number of animals is indicated in parentheses or inside plot bars. Data represent mean \pm SEM. $\boldsymbol{H}-J$, Immunofluorescence staining for the neuronal marker NeuN in coronal brain sections (top) and thickness measurements (bottom) from SSC $(\boldsymbol{H}), \mathrm{MC}(\boldsymbol{I})$, and DG (J) granule cell layer from $6 \mathrm{mo}$ (Ctrol and tTA/ $\Delta \mathrm{NLS}$ ) and $6 \mathrm{mo}\left(\right.$ sup) mice. ${ }^{*} p<0.05$; ${ }^{* *} p<$ $0.01 ;{ }^{* * *} p<0.001$, one-way ANOVA/Newman-Keuls post hoc test. Scale bars: $\boldsymbol{H}$ and $\boldsymbol{I}, 250$ $\mu \mathrm{m} ; J, 50 \mu \mathrm{m}$. Data represent mean \pm SEM ( $n=4$ per group). sate for the alterations elicited by TDP-43- $\Delta$ NLS overexpression. These results suggest that TDP-43-mediated behavioral dysfunction is sustained by functional changes in populations of affected neurons independently of extensive neurodegeneration and that diverse symptoms might have different susceptibility to amelioration.

It has been reported previously that overexpression of diverse TDP-43 species using viral or transgenic approaches has an impact in different (mostly motor) behavioral measures in mouse, rat, and primate animal models (Tsai et al., 2010; Zhou et al., 2010; Igaz et al., 2011; Swarup et al., 2011; Caccamo et al., 2012; Uchida et al., 2012; Dayton et al., 2013). The impairment of motor, cognitive, and social function observed in our mouse model correlates poorly with TDP-43 aggregation and cleavage because the occurrence of pathological TDP-43-positive accumulations and proteolytic fragments is minimal or nonexistent in these mice (Igaz et al., 2011). In addition, a full-blown behavioral phenotype is rapidly established after Tg induction in young mice in the absence of massive neurodegeneration. Moreover, motor and cognitive functions are remarkably ameliorated after Tg suppression. These findings underscore the notion that some behavioral deficits in young mice are more likely the result of abnormal neuronal function of TDP-43- $\Delta$ NLS-expressing cells, which are still alive and participate in the relevant circuits, rather than being due to the mere loss of a specific population of neurons. Because continuous Tg expression for 6 months led to overt neurodegeneration, as indicated by gross atrophy of cortical and granule cell layers, one might speculate that a critical threshold of neuronal loss has been reached beyond which no renormalization of neuronal function can be reached by Tg suppression. However, it must be pointed out that although the time frame that we used for suppression might be sufficient to reverse some deficits at younger age, longer suppression periods might be required for recovery of behavioral function in animals exposed to extended Tg expression.

A novel cytoplasmic role for TDP-43 has been described recently (Alami et al., 2014). TDP-43 functions in the cytoplasm to transport mRNA granules selectively in a predominantly anterograde manner and alterations in this process (either by familial mutations or unknown factors) might have direct consequences that contribute to selective degeneration of cellular subtypes, specifically neurons. In addition, it is becoming increasingly clear that the FTD-ALS spectrum is not only a disorder of proteostasis, but also of RNA homeostasis (Ling et al., 2013; Ramaswami et al., 2013). Our animal model might be useful to address in vivo some of these issues, because reversible overexpression of a cytoplasmic form of TDP-43 might modify the assembly, distribution, composition, and transport of these mRNA granules, with implications for neuronal function and survival.

Cognitive and social dysfunction has been reported in FTD rodent models (Roberson, 2012) mainly in tau-based mice, but also in different valosin-containing protein (VCP), progranulin (PRGN), and TDP-43 transgenic animals. Neuronal overexpression of a disease-associated VCP mutation led to age-dependent ubiquitin and TDP-43 accumulation and decline in cognitive function, including deficits in spatial memory, object recognition, and fear conditioning (Rodriguez-Ortiz et al., 2013). PRGN-deficient mice, which model PGRN haploinsufficiencyrelated FTD, display early changes in social behavior and latestage impairment in spatial learning and memory as assessed in the Morris water maze. These deficits were associated with neuropathological changes such as accumulation of ubiquitin and 
cytosolic phosphorylated TDP-43 in the hippocampus (Yin et al., 2010). Social and cognitive abnormalities were also recapitulated in other PRGN-deficient mice (Ghoshal et al., 2012; Petkau et al., 2012). TDP-43 transgenic and viral-based models also showed different degrees of cognitive impairment, including those overexpressing TDP-43 C-terminal fragments, disease-associated mutations, or even the wild-type protein (Tsai et al., 2010; Swarup et al., 2011; Caccamo et al., 2012; Dayton et al., 2012; Dayton et al., 2013). Remarkably, social dysfunction has not been described previously in TDP-43-based models of disease, underscoring the fact that our Tg mice might provide a platform for studying this rapidly established and nonreversible phenotype.

Although finding behavioral assays to properly characterize FTD mouse models might seem challenging, there are several features that are amenable to behavioral analysis in rodents. For example, social dysfunction is an aspect of FTD that can be examined in mice and social tests have proven to be useful in disorders with prominent social deficits such as autism (Crawley, 2007). Another symptom that can be assessed is repetitive behavior, which is characteristic of FTD and can become disabling (Mendez et al., 2005). In this study, we analyzed both of these features to understand more comprehensively the behavioral abnormalities in our mice. Recent reports describe striatal degeneration in FTD patients (Halabi et al., 2013), a subcortical structure relevant for social and emotional processing (Báez-Mendoza and Schultz, 2013; Nieh et al., 2013). In our mice, the CaMKII $\alpha$ promoter drives Tg expression in striatal neurons, potentially contributing to some of the deficits described here. Impaired fear processing can also be assessed in Tg mouse models using fear conditioning and other aversive paradigms to evaluate amygdalar dysfunction, which is also associated with FTD (Hoefer et al., 2008). TDP-43- $\Delta$ NLS mice display abnormal fear-related behavior as assessed by inhibitory avoidance, a hippocampal and amygdala-dependent aversive task (Cammarota et al., 2008).

One of the limitations of our model is originated by the very same feature that provides specificity of Tg expression. Although "cleaner" than pan-neuronal promoters, the forebrain-enriched pattern of neuronal expression provided by the CaMKII $\alpha$ promoter also introduces a bias in the behavioral effects provoked by TDP-43- $\Delta$ NLS expression. It would certainly be informative to compare the toxicity and functional changes elicited by expressing this $\mathrm{Tg}$ in a different cell population (i.e., spinal cord motor neurons). Although some of the transgenic tools to undertake these studies are currently available, these models can provide little or limited information due to early lethality or pleiotropic effects that might obscure the interpretation of behavioral data.

The remarkably rapid effect of postweaning Tg expression on several behavioral domains prompted us to propose that normal TDP-43 roles are being disrupted by TDP-43- $\Delta$ NLS and that this leads to altered functionality of the affected neurons. Although TDP-43- $\Delta$ NLS expression has been shown to be primarily cytoplasmic both in vitro and in vivo by other laboratories and our previous work (Winton et al., 2008; Igaz et al., 2011; Miguel et al., 2011; Dayton et al., 2013), it cannot be excluded that residual transgene expression in the nucleus may contribute to the phenotype observed here. Several reports show that manipulation of TDP-43 levels or subcellular localization have a profound impact in mRNA/microRNA levels and mRNA splicing patterns, among other TDP-43 downstream effects (Buratti et al., 2010; Igaz et al., 2011; Polymenidou et al., 2011; Tollervey et al., 2011; Kawahara and Mieda-Sato, 2012; Zhang et al., 2013). Moreover, because short-term Tg suppression reverses some behavioral deficits and halts neurodegeneration in affected brain regions, we interpret this to mean that the majority of TDP-43- $\Delta$ NLS-expressing neurons recover and are capable of properly sustaining the behaviors we tested when they belong to circuits or structures that have not suffered from major neurodegeneration (as demonstrated in young mice). This would not be the case for animals that present severe neuronal death (i.e., 6 months off Dox) and cannot revert to a normal phenotype after suppression. We consider this to be a relevant hypothesis that can be addressed by in vitro and in vivo electrophysiological methods applied to our animal model. Further analysis will be required to determine whether basal synaptic transmission and synaptic plasticity is altered in TDP-43- $\Delta$ NLS mice.

In sum, we propose that inducible TDP-43- $\Delta$ NLS mice constitute a novel and useful model of TDP-43 proteinopathies such as FTLD-TDP and FTLD-MND and might provide a versatile platform to perform pharmacological, electrophysiological, and behavioral studies to better understand the pathophysiology of these devastating and incurable diseases.

\section{References}

Alami NH, Smith RB, Carrasco MA, Williams LA, Winborn CS, Han SS, Kiskinis E, Winborn B, Freibaum BD, Kanagaraj A, Clare AJ, Badders NM, Bilican B, Chaum E, Chandran S, Shaw CE, Eggan KC, Maniatis T, Taylor JP (2014) Axonal transport of TDP-43 mRNA granules is impaired by ALS-causing mutations. Neuron 81:536-543. CrossRef Medline

Aviles-Reyes RX, Angelo MF, Villarreal A, Rios H, Lazarowski A, Ramos AJ (2010) Intermittent hypoxia during sleep induces reactive gliosis and limited neuronal death in rats: implications for sleep apnea. J Neurochem 112:854-869. CrossRef Medline

Báez-Mendoza R, Schultz W (2013) The role of the striatum in social behavior. Front Neurosci 7:233. CrossRef Medline

Belforte JE, Zsiros V, Sklar ER, Jiang Z, Yu G, Li Y, Quinlan EM, Nakazawa K (2010) Postnatal NMDA receptor ablation in corticolimbic interneurons confers schizophrenia-like phenotypes. Nat Neurosci 13:76-83. CrossRef Medline

Boccia MM, Acosta GB, Blake MG, Baratti CM (2004) Memory consolidation and reconsolidation of an inhibitory avoidance response in mice: effects of i.c.v. injections of hemicholinium-3. Neuroscience 124:735741. CrossRef Medline

Brodkin ES, Hagemann A, Nemetski SM, Silver LM (2004) Social approachavoidance behavior of inbred mouse strains towards DBA/2 mice. Brain Res 1002:151-157. CrossRef Medline

Buratti E, De Conti L, Stuani C, Romano M, Baralle M, Baralle F (2010) Nuclear factor TDP-43 can affect selected microRNA levels. FEBS J 277: 2268-2281. CrossRef Medline

Caccamo A, Majumder S, Oddo S (2012) Cognitive decline typical of frontotemporal lobar degeneration in transgenic mice expressing the $25-\mathrm{kDa}$ C-terminal fragment of TDP-43. Am J Pathol 180:293-302. CrossRef Medline

Cammarota M, Bevilaqua LR, Rossato JI, Lima RH, Medina JH, Izquierdo I (2008) Parallel memory processing by the CA1 region of the dorsal hippocampus and the basolateral amygdala. Proc Natl Acad Sci U S A 105: 10279-10284. CrossRef Medline

Cannon A, Yang B, Knight J, Farnham IM, Zhang Y, Wuertzer CA, D'Alton S, Lin WL, Castanedes-Casey M, Rousseau L, Scott B, Jurasic M, Howard J, Yu X, Bailey R, Sarkisian MR, Dickson DW, Petrucelli L, Lewis J (2012) Neuronal sensitivity to TDP-43 overexpression is dependent on timing of induction. Acta Neuropathol 123:807-823. CrossRef Medline

Crawley JN (2007) Mouse behavioral assays relevant to the symptoms of autism. Brain Pathol 17:448-459. CrossRef Medline

Dayton RD, Wang DB, Cain CD, Schrott LM, Ramirez JJ, King MA, Klein RL (2012) Frontotemporal lobar degeneration-related proteins induce only subtle memory-related deficits when bilaterally overexpressed in the dorsal hippocampus. Exp Neurol 233:807-814. CrossRef Medline 
Dayton RD, Gitcho MA, Orchard EA, Wilson JD, Wang DB, Cain CD, Johnson JA, Zhang YJ, Petrucelli L, Mathis JM, Klein RL (2013) Selective forelimb impairment in rats expressing a pathological TDP-43 $25 \mathrm{kDa}$ C-terminal fragment to mimic amyotrophic lateral sclerosis. Mol Ther 21:1324-1334. CrossRef Medline

Depino AM, Lucchina L, Pitossi F (2011) Early and adult hippocampal TGF-betal overexpression have opposite effects on behavior. Brain Behav Immun 25:1582-1591. CrossRef Medline

Ghoshal N, Dearborn JT, Wozniak DF, Cairns NJ (2012) Core features of frontotemporal dementia recapitulated in progranulin knockout mice. Neurobiol Dis 45:395-408. CrossRef Medline

Gitcho MA, Baloh RH, Chakraverty S, Mayo K, Norton JB, Levitch D, Hatanpaa KJ, White CL 3rd, Bigio EH, Caselli R, Baker M, Al-Lozi MT, Morris JC, Pestronk A, Rademakers R, Goate AM, Cairns NJ (2008) TDP-43 A315T mutation in familial motor neuron disease. Ann Neurol 63:535538. CrossRef Medline

Halabi C, Halabi A, Dean DL, Wang PN, Boxer AL, Trojanowski JQ, Dearmond SJ, Miller BL, Kramer JH, Seeley WW (2013) Patterns of striatal degeneration in frontotemporal dementia. Alzheimer Dis Assoc Disord 27:74-83. CrossRef Medline

Hoefer M, Allison SC, Schauer GF, Neuhaus JM, Hall J, Dang JN, Weiner MW, Miller BL, Rosen HJ (2008) Fear conditioning in frontotemporal lobar degeneration and Alzheimer's disease. Brain 131:1646-1657. CrossRef Medline

Igaz LM, Kwong LK, Xu Y, Truax AC, Uryu K, Neumann M, Clark CM, Elman LB, Miller BL, Grossman M, McCluskey LF, Trojanowski JQ, Lee VM (2008) Enrichment of C-terminal fragments in TAR DNA-binding protein- 43 cytoplasmic inclusions in brain but not in spinal cord of frontotemporal lobar degeneration and amyotrophic lateral sclerosis. Am J Pathol 173:182-194. CrossRef Medline

Igaz LM, Kwong LK, Lee EB, Chen-Plotkin A, Swanson E, Unger T, Malunda J, Xu Y, Winton MJ, Trojanowski JQ, Lee VM (2011) Dysregulation of the ALS-associated gene TDP-43 leads to neuronal death and degeneration in mice. J Clin Invest 121:726-738. CrossRef Medline

Kabashi E, Valdmanis PN, Dion P, Spiegelman D, McConkey BJ, Vande Velde C, Bouchard JP, Lacomblez L, Pochigaeva K, Salachas F, Pradat PF, Camu W, Meininger V, Dupre N, Rouleau GA (2008) TARDBP mutations in individuals with sporadic and familial amyotrophic lateral sclerosis. Nat Genet 40:572-574. CrossRef Medline

Kawahara Y, Mieda-Sato A (2012) TDP-43 promotes microRNA biogenesis as a component of the Drosha and Dicer complexes. Proc Natl Acad Sci U S A 109:3347-3352. CrossRef Medline

Ling SC, Polymenidou M, Cleveland DW (2013) Converging mechanisms in ALS and FTD: disrupted RNA and protein homeostasis. Neuron 79: 416-438. CrossRef Medline

Mayford M, Bach ME, Huang YY, Wang L, Hawkins RD, Kandel ER (1996) Control of memory formation through regulated expression of a CaMKII transgene. Science 274:1678-1683. CrossRef Medline

Mendez MF, Shapira JS, Miller BL (2005) Stereotypical movements and frontotemporal dementia. Mov Disord 20:742-745. CrossRef Medline

Metz GA, Schwab ME (2004) Behavioral characterization in a comprehensive mouse test battery reveals motor and sensory impairments in growthassociated protein-43 null mutant mice. Neuroscience 129:563-574. CrossRef Medline

Miguel L, Frébourg T, Campion D, Lecourtois M (2011) Both cytoplasmic and nuclear accumulations of the protein are neurotoxic in Drosophila models of TDP-43 proteinopathies. Neurobiol Dis 41:398-406. CrossRef Medline

Moy SS, Nadler JJ, Perez A, Barbaro RP, Johns JM, Magnuson TR, Piven J, Crawley JN (2004) Sociability and preference for social novelty in five inbred strains: an approach to assess autistic-like behavior in mice. Genes Brain Behav 3:287-302. CrossRef Medline

Neumann M, Sampathu DM, Kwong LK, Truax AC, Micsenyi MC, Chou TT, Bruce J, Schuck T, Grossman M, Clark CM, McCluskey LF, Miller BL, Masliah E, Mackenzie IR, Feldman H, Feiden W, Kretzschmar HA, Trojanowski JQ, Lee VM (2006) Ubiquitinated TDP-43 in frontotemporal lobar degeneration and amyotrophic lateral sclerosis. Science 314:130133. CrossRef Medline

Nieh EH, Kim SY, Namburi P, Tye KM (2013) Optogenetic dissection of neural circuits underlying emotional valence and motivated behaviors. Brain Res 1511:73-92. CrossRef Medline
Paxinos G, Franklin KBJ (2008) The mouse brain in stereotaxic coordinates. New York: Elsevier Academic.

Petkau TL, Neal SJ, Milnerwood A, Mew A, Hill AM, Orban P, Gregg J, Lu G, Feldman HH, Mackenzie IR, Raymond LA, Leavitt BR (2012) Synaptic dysfunction in progranulin-deficient mice. Neurobiol Dis 45:711-722. CrossRef Medline

Polymenidou M, Lagier-Tourenne C, Hutt KR, Huelga SC, Moran J, Liang TY, Ling SC, Sun E, Wancewicz E, Mazur C, Kordasiewicz H, Sedaghat Y, Donohue JP, Shiue L, Bennett CF, Yeo GW, Cleveland DW (2011) Long pre-mRNA depletion and RNA missplicing contribute to neuronal vulnerability from loss of TDP-43. Nat Neurosci 14:459-468. CrossRef Medline

Ramaswami M, Taylor JP, Parker R (2013) Altered ribostasis: RNA-protein granules in degenerative disorders. Cell 154:727-736. CrossRef Medline

Roberson ED (2012) Mouse models of frontotemporal dementia. Ann Neurol 72:837-849. CrossRef Medline

Robertson CL, Puskar A, Hoffman GE, Murphy AZ, Saraswati M, Fiskum G (2006) Physiologic progesterone reduces mitochondrial dysfunction and hippocampal cell loss after traumatic brain injury in female rats. Exp Neurol 197:235-243. CrossRef Medline

Rodriguez-Ortiz CJ, Hoshino H, Cheng D, Liu-Yescevitz L, Blurton-Jones M, Wolozin B, LaFerla FM, Kitazawa M (2013) Neuronal-specific overexpression of a mutant valosin-containing protein associated with IBMPFD promotes aberrant ubiquitin and TDP-43 accumulation and cognitive dysfunction in transgenic mice. Am J Pathol 183:504-515. CrossRef Medline

Rutherford NJ, Zhang YJ, Baker M, Gass JM, Finch NA, Xu YF, Stewart H, Kelley BJ, Kuntz K, Crook RJ, Sreedharan J, Vance C, Sorenson E, Lippa C, Bigio EH, Geschwind DH, Knopman DS, Mitsumoto H, Petersen RC, Cashman NR, Hutton M, Shaw CE, Boylan KB, Boeve B, Graff-Radford NR, Wszolek ZK, Caselli RJ, Dickson DW, Mackenzie IR, Petrucelli L, Rademakers R (2008) Novel mutations in TARDBP (TDP-43) in patients with familial amyotrophic lateral sclerosis. PLoS Genet 4:e1000193. CrossRef Medline

Salinger WL, Ladrow P, Wheeler C (2003) Behavioral phenotype of the Reeler mutant mouse: effects of reln gene dosage and social isolation. Behav Neurosci 117:1257-1275. CrossRef Medline

Seeley WW (2008) Selective functional, regional, and neuronal vulnerability in frontotemporal dementia. Curr Opin Neurol 21:701-707. CrossRef Medline

Sreedharan J, Blair IP, Tripathi VB, Hu X, Vance C, Rogelj B, Ackerley S, Durnall JC, Williams KL, Buratti E, Baralle F, de Belleroche J, Mitchell JD, Leigh PN, Al-Chalabi A, Miller CC, Nicholson G, Shaw CE (2008) TDP-43 mutations in familial and sporadic amyotrophic lateral sclerosis. Science 319:1668-1672. CrossRef Medline

Swarup V, Phaneuf D, Bareil C, Robertson J, Rouleau GA, Kriz J, Julien JP (2011) Pathological hallmarks of amyotrophic lateral sclerosis/frontotemporal lobar degeneration in transgenic mice produced with TDP-43 genomic fragments. Brain 134:2610-2626. CrossRef Medline

Tollervey JR, Curk T, Rogelj B, Briese M, Cereda M, Kayikci M, König J, Hortobágyi T, Nishimura AL, Zupunski V, Patani R, Chandran S, Rot G, Zupan B, Shaw CE, Ule J (2011) Characterizing the RNA targets and position-dependent splicing regulation by TDP-43. Nat Neurosci 14:452458. CrossRef Medline

Tsai KJ, Yang CH, Fang YH, Cho KH, Chien WL, Wang WT, Wu TW, Lin CP, $\mathrm{Fu}$ WM, Shen CK (2010) Elevated expression of TDP-43 in the forebrain of mice is sufficient to cause neurological and pathological phenotypes mimicking FTLD-U. J Exp Med 207:1661-1673. CrossRef Medline

Tsao W, Jeong YH, Lin S, Ling J, Price DL, Chiang PM, Wong PC (2012) Rodent models of TDP-43: recent advances. Brain Res 1462:26-39. CrossRef Medline

Uchida A, Sasaguri H, Kimura N, Tajiri M, Ohkubo T, Ono F, Sakaue F, Kanai K, Hirai T, Sano T, Shibuya K, Kobayashi M, Yamamoto M, Yokota S, Kubodera T, Tomori M, Sakaki K, Enomoto M, Hirai Y, Kumagai J, Yasutomi Y, Mochizuki H, Kuwabara S, Uchihara T, Mizusawa H, Yokota T (2012) Non-human primate model of amyotrophic lateral sclerosis with cytoplasmic mislocalization of TDP-43. Brain 135:833-846. CrossRef Medline

Wang IF, Wu LS, Chang HY, Shen CK (2008) TDP-43, the signature protein of FTLD-U, is a neuronal activity-responsive factor. J Neurochem 105: 797-806. CrossRef Medline 
Wegorzewska I, Bell S, Cairns NJ, Miller TM, Baloh RH (2009) TDP-43 mutant transgenic mice develop features of ALS and frontotemporal lobar degeneration. Proc Natl Acad Sci U S A 106:18809-18814. CrossRef Medline

Winton MJ, Igaz LM, Wong MM, Kwong LK, Trojanowski JQ, Lee VM (2008) Disturbance of nuclear and cytoplasmic TAR DNA-binding protein (TDP-43) induces disease-like redistribution, sequestration, and aggregate formation. J Biol Chem 283:13302-13309. CrossRef Medline

Yin F, Dumont M, Banerjee R, Ma Y, Li H, Lin MT, Beal MF, Nathan C, Thomas B, Ding A (2010) Behavioral deficits and progressive neuropathology in progranulin-deficient mice: a mouse model of frontotemporal dementia. FASEB J 24:4639-4647. CrossRef Medline
Yokoseki A, Shiga A, Tan CF, Tagawa A, Kaneko H, Koyama A, Eguchi H, Tsujino A, Ikeuchi T, Kakita A, Okamoto K, Nishizawa M, Takahashi H, Onodera O (2008) TDP-43 mutation in familial amyotrophic lateral sclerosis. Ann Neurol 63:538-542. CrossRef Medline

Zhang Z, Almeida S, Lu Y, Nishimura AL, Peng L, Sun D, Wu B, Karydas AM, Tartaglia MC, Fong JC, Miller BL, Farese RV Jr, Moore MJ, Shaw CE, Gao FB (2013) Downregulation of microRNA-9 in iPSC-derived neurons of FTD/ALS patients with TDP-43 mutations. PLoS One 8:e76055. CrossRef Medline

Zhou H, Huang C, Chen H, Wang D, Landel CP, Xia PY, Bowser R, Liu YJ, Xia XG (2010) Transgenic rat model of neurodegeneration caused by mutation in the TDP gene. PLoS Genet 6:e1000887. CrossRef Medline 